\title{
MÚSICA E IDENTIDAD NACIONAL EN LA ESPAÑA DE ENTREGUERRAS: LOS CONCIERTOS POPULARES DEL CÍRCULO DE BELLAS ARTES (1914-1924)
}

\author{
Beatriz Martínez del Fresno \\ Universidad de Oviedo
}

\begin{abstract}
RESUMEN
En 1914 el Círculo de Bellas Artes de Madrid estableció la fórmula de los conciertos populares con la intención de difundir la forma "más elevada y pura del arte lírico" entre la "gran masa española". A través de sus actuaciones, la Orquesta Filarmónica dirigida por Bartolomé Pérez Casas contribuyó a consolidar una escuela sinfónica nacional, estrenando con regularidad nuevas obras y repitiendo las ya conocidas. Este proceso es analizado desde tres ángulos: la perspectiva de la entidad artístico-recreativa, los procedimientos utilizados por los compositores para dotar a su música de una significación nacional y la recepción de las obras por una audiencia entusiasta. Con ello, se trata de valorar la medida en que en estas "fiestas artísticas" se definió una identidad cultural acorde con el perfil mesocrático del público que acudía al teatro Price.
\end{abstract}

Palabras clave: identidad nacional, música española, Círculo de Bellas Artes, Orquesta Filarmónica de Madrid, conciertos populares

\begin{abstract}
In 1914 the Círculo de Bellas Artes de Madrid (Madrid Fine Arts Society) began organising popular concerts with the intention of disseminating "the highest and purest form of lyrical art" among "the Spanish masses". Through its performances, the Philharmonic Orchestra, conducted by Bartolome Perez Casas, helped consolidate a national symphonic school, premiering new works on a regular basis and performing existing ones. This process is analysed from three angles: The perspective of the artistic/recreational group, the procedures used by composers to instil their music with national meaning, and the way in which works were received by an enthusiastic audience. The aim in doing so is to assess the extent to which these "artistic festivals" forged a cultural identity that tied in with the bourgeois nature of the audiences at the Teatro Price.
\end{abstract}

Keywords: national identity, spanish music, Círculo de Bellas Artes (Fine Arts Society), Madrid Philharmonic Orchestra, popular concerts

Reflexionar sobre la forma en que la música participó en los procesos de identidad nacional desarrollados en España significa retomar un tema tratado fragmentaria pero insistentemente por la musicología española. Con frecuencia el análisis de los discursos de compositores y críticos del período 1900-1936 ha girado en torno al "nacionalismo musical" , un complejo y difuso concepto que en realidad ha atravesado, de una u otra manera, la historia y la historiografía de la música española de los siglos XIX y XX.
La vieja idea sobre el nacionalismo musical suponía que este se podía concretar en un estilo con sus correspondientes características formales, derivadas principalmente de la elección de elementos folclóricos o tradicionales, y de la forma en que el compositor insertaba y desarrollaba estos materiales dentro de los géneros cultos. Desde la perspectiva del canon occidental de la música, esa contaminación del lenguaje sonoro -concebido utópicamente como universal- a base de referencias locales y rústicas 
entraña implícitamente una pérdida de autonomía del arte musical ya que la libertad del artista se ve mermada desde el momento en que, por su condición de compositor nacionalista, debe orientar su numen hacia la búsqueda de un estilo que, por definición, ha de ser consensuado colectivamente. Esta explicación se complementa, naturalmente, con el carácter periférico de algunas naciones, que solo aparecen en la bibliografía musicológica europea o norteamericana de la mano de los movimientos de reivindicación nacionalista, sea en clave política o en clave cultural, frente a la música universal que, según el relato oficial, habría sido producida sucesiva o alternativamente por los países de habla italiana, francesa y, sobre todo, alemana.

Ante este modelo, entendemos hoy que las relaciones entre el estilo internacional y cosmopolita y los estilos nacionales están lejos de ser simples, unívocas y de una sola dirección. Un punto de vista crítico ante el eurocentrismo y la visión colonialista ha permitido detectar las falacias en la presuposición de que Alemania, Italia o Francia no han producido música, discursos o acciones nacionalistas. Nada más lejos de la realidad $^{2}$. También somos conscientes de que, aunque en ocasiones se haya visto silenciada u olvidada, los países periféricos han tenido siempre música, antes, durante y después de su entrada en el circuito cosmopolita europeo y de que su pálido reflejo se incluya en la bibliografía internacional. Dicho con otras palabras, es la mirada eurocéntrica la que ha asignado ese papel periférico a ciertas manifestaciones artísticas o musicales, impuesta por quien necesita o desea constituirse como centro.

Por otra parte, si aceptamos que el nacionalismo musical depende en gran medida de los discursos creados alrededor de la música — sean estos producidos por los políticos, los compositores, los intelectuales o la crítica- y de la forma en que el material sonoro se percibe y resignifi$\mathrm{Ca}^{3}$, hemos de reconocer que tanto los escritos de los artistas como los comentarios de las publicaciones periódicas pueden proporcionar a los investigadores un océano de materiales para analizar este fenómeno en la España de los siglos XIX y XX. El problema de fondo es cómo y desde qué marco teórico hacer ese análisis, evitando el estilo esencialista que ese material ha venido generando o sorteando la perspectiva emic de la musicología que no consigue mantener la suficiente distancia respecto al tema.

Independientemente de lo que atañe a nuestro país, las aportaciones de los estudios culturales y de la musicología crítica han incidido de lleno en este tema, el del nacionalismo musical, que se presta de manera natural a una lectura sociopolítica de la cultura y el arte. Tratando de evitar esencialismos y primordialismos, esta nueva mirada ha venido a subrayar la carga ideológica y política del nacionalismo musical —que ya no tendría sentido, como antaño, reducir a un catálogo de formas o fórmulas estilísticas - y, lo que es más importante, a poner de relieve el papel activo que la música desempeña en la construcción de lo nacional.

Paralelamente, se han establecido interpretaciones que, sin excluir el estudio de las obras musicales, las ponen en relación con los discursos y las prácticas, atendiendo de manera novedosa a los aspectos performativos de la música, pocas veces contemplados por una musicología demasiado pendiente de la partitura, que objetualiza en ella el sonido 4 . A la hora de determinar el valor o el peso nacionalista de un producto o de un proceso, el mercado científico ofrece ahora diversas combinaciones entre la creación, la interpretación y la recepción.

Por lo que respecta al período en el que nos vamos a adentrar, cabe señalar la fuerte nacionalización de las actividades musicales de la España de entreguerras, visible tanto en lo que atañe a la discusión sobre los elementos genético-estructurales de la nación (la lengua, la tradición, la historia, la raza, el volksgeist) como en los niveles relacionales, campo en que se van a establecer diversos referentes de identificación, integración y exclusión ${ }^{5}$. En este segundo aspecto encontramos una gama de posturas y combinaciones en el debate entre casticismo, regionalismo, nacionalismo y universalismo, y, por si no fuera bastante complejo, ese debate se entremezcla frecuentemente con la disyuntiva entre la tradición y la modernización del lenguaje musical.

Merecería la pena igualmente estudiar las diferentes estrategias organizativas de las actividades musicales, en las que los distintos secto- 
res sociales y grupos de élite van interviniendo. Desde las aspiraciones expresadas alrededor de la creación de la Sociedad Nacional de Música en 1915 hasta los programas de política musical establecidos durante la Segunda República española y en los años de la Guerra Civil, son muchos los estratos que aún requieren estudios pormenorizados. Trataremos de examinar aquí un programa de actuación concreto, que nos va a situar en un plano intermedio entre la visión de toda una época - la España de entreguerras - y la trayectoria individual de un compositor o el seguimiento de un género en particular.

\section{La fórmula de los conciertos populares del Círculo de Bellas Artes}

Los conciertos populares del Círculo constituyeron un proyecto muy novedoso en Madrid, donde en ese momento había una escasa tradición sinfónica y las pocas actuaciones orquestales que la ciudad ofrecía no se dirigían a un público tan amplio como el que durante años iba a acudir al circo Price.

En una nota incluida en el programa de la primera serie, el Círculo de Bellas Artes explicó que en beneficio de la cultura patria había decidido apoyar la afición musical de las clases menos pudientes. Era una bonita declaración de intenciones al inicio de un proyecto que, andando el tiempo, había de desarrollarse de manera efectiva y con una acogida sorprendente. La nota decía así:

El Círculo de Bellas Artes, atento siempre, dentro de su esfera de acción, a cuanto pueda redundar en beneficio de la cultura patria, ha estimado que debe aprovechar las especiales inclinaciones que se advierten entre las clases menos pudientes de Madrid, en favor de la afición musical.

La devoción y entusiasmo con que se escucha, cada vez con más público, la admirable Banda Municipal; el brillante éxito de la campaña de zarzuela del pasado año y de la ópera éste en el Teatro de Price; el resurgimiento lírico español con los nombres de Usandizaga, Del Campo, Vives, Turina, Millán, Falla, etc., demuestra que, contra lo que generalmente se propala, Madrid tiene amor a la música, que va fervientemente a buscarla siempre que ella se encuentre al alcance económico de las clases poco adineradas.

Los conciertos sinfónicos, forma la más elevada y pura del arte lírico, apenas tienen manifestación en Madrid, dándose el caso, único en Europa, de que la capital de la nación dé solo seis audiciones anuales en el Real, no obstante la suerte de contar con una orquesta de profesores clamorosamente aplaudida en el extranjero y elogiada por cuantos maestros la escucharon y dirigieron.

El Círculo de Bellas Artes, recogiendo este ambiente, va a intentar generosamente lo que no podría hacer una empresa industrial ante el seguro fracaso económico; contratar la Sinfónica, y los viernes de cada semana por la tarde, y a precios populares, en un teatro céntrico, amplio, de localidad barata, ofrecer a los aficionados de Madrid, este año, tres conciertos, ampliándolos los venideros según marque $u$ obligue el resultado de este ensayo, dando en ellos lo mejor y lo más selecto de los programas acostumbrados.

El Círculo entrega la propaganda de estos conciertos, el éxito de este cultísimo proyecto, al entusiasmo de los aficionados madrileños, a los estímulos de esa gran masa española que clama a diario contra nuestro atraso espiritual y que sólo espera, según dice, entidades o elementos impulsivos que los congregue y les marque altos derroteros que seguir. ${ }^{6}$

La iniciativa había tomado forma un par de meses antes, cuando, a propuesta del entonces presidente de la Sección de Música, Tomás Bretón, secundado por Emilio Serrano, se había presentado un proyecto que la directiva del Círculo aprobó en su sesión del 6 de noviembre de 1914. Fundar conciertos populares era una vieja aspiración de Bretón, que ya la había expresado en algunas memorias del Conservatorio de Madrid ${ }^{7}$.

En efecto, el público de la capital española respondió decididamente a la iniciativa y las sucesivas series - primero en el teatro Price y 
después en otros lugares- llegarían a alcanzar en 1928 las catorce temporadas y el número de 190 conciertos populares ${ }^{8}$. Una multitud ávida de consumir los productos culturales de la gran música sinfónica, con Beethoven y Wagner como compositores emblemáticos, fue aprendiendo a admirar también a otros románticos y nacionalistas, así como a una galería de autores contemporáneos, principalmente rusos y franceses.

La etapa más brillante de esta iniciativa del Círculo fue sin duda la que transcurrió entre 1914 y 1924, los años en que los conciertos populares se llevaron a cabo en el circo de Price (también llamado circo de Parish, por el nombre de su propietario), un teatro diseñado por el arquitecto Agustín Ortiz de Villajos que se había construido en $1880^{\circ}$. El edificio tenía una planta poligonal de dieciséis lados y estaba sostenido por una estructura de hierro con arcos neoárabes que se correspondían con el estilo de la decoración exterior (Fig. 1).

Además de su céntrico emplazamiento en la madrileña plaza del Rey, entre las ventajas del circo se destacaban el precio al que la empresa lo cedía - 525 pesetas - y su amplio aforo. El interior del Price se distribuía en 26 palcos, 600 butacas, 140 delanteras bajas, 160 delanteras de arriba, 137 sillas de segunda fila y más de 2.000 entradas generales. De la suma resulta un aforo generoso que supera las 3.000 plazas.

La documentación relativa a los primeros conciertos populares diferencia cuatro niveles de localidades, con unos precios iniciales de 18 pesetas por los palcos de cinco entradas, 3 pesetas por las butacas, 2 por las sillas de delantera de anfiteatro, 1,25 por las delanteras de grada, y 0,75 pesetas por las sillas de galería y entradas generales ${ }^{10}$. A partir de la segunda temporada se produjeron ligeras subidas en los precios, pero las entradas más baratas no pasarían de costar 1,50 y 1 peseta respectivamente.

Teniendo en cuenta que la agrupación orquestal -en un primer momento la Sinfónica, enseguida sustituida por la Filarmónica - empezó cobrando 2.500 pesetas por concierto 11 y que a ello se sumaban los gastos habituales en la vida teatral (alquiler del teatro, impuestos, recibos de la sociedad de autores, cartelería, taquilla, acomodadores, decoración...), cada sesión venía a costar, de media, unas 3.800 pesetas. Se confiaba en que la entrada, a precios módicos, sería numerosa y de ese modo el concierto se autofinanciaría, o casi. Puesto que el proyecto no tenía ninguna intención lucrativa, el Círculo asumía con gusto el posible déficit, satisfecho de la importante labor realizada en aras de la difusión de la cultura musical' ${ }^{12}$. No obstante, esta iniciativa implicaba un cierto riesgo porque dependía directamente de la concurrencia y, tanto si era superávit como déficit, el resultado afectaría a las cuentas de la Sección de Música, cuyo presupuesto total para el año 1917, por ejemplo, era de 7.900 pesetas $^{13}$, teniendo que atender con esa cantidad el coste de las veladas musicales, las becas de estudio, las pensiones a músicos y otras actividades.

El Círculo trató de difundir la forma "más elevada y pura del arte lírico" entre la "gran masa española", pero además de ese altruista interés cultural y social, la documentación consultada demuestra que, a la hora de programar, tanto la Orquesta Filarmónica como el Círculo de Bellas Artes se preocuparon siempre por apoyar la música nacional (Fig. 2).

En sus estatutos de 1915 la primera entidad señalaba que la nueva orquesta tenía por objeto "dar conciertos para contribuir directamente al fomento, difusión y enseñanza de la música sinfónica y el de laborar por el arte y artistas patrios" 14 . Uno de los programas de los conciertos populares expresará más tarde la vocación educativa y divulgativa de la Orquesta Filarmónica de Madrid, así como su política respecto a la música nueva, que solo fue posible gracias al esfuerzo de Pérez Casas y de sus músicos, dispuestos a desentrañar nuevas partituras para cada concierto (Fig. 3):

La Orquesta Filarmónica, atenta a la labor educativa que se ha impuesto, no ha reparado en dificultades ni gastos, excesivos en las actuales circunstancias, para adquirir gran número de obras de todas las escuelas y tendencias [...]. La mayoría de esas obras son tan difíciles de ejecución como de comprensión, y si bien han sido plenamente admitidas en los programas mundiales, es necesario no olvidar que, tanto los artistas 


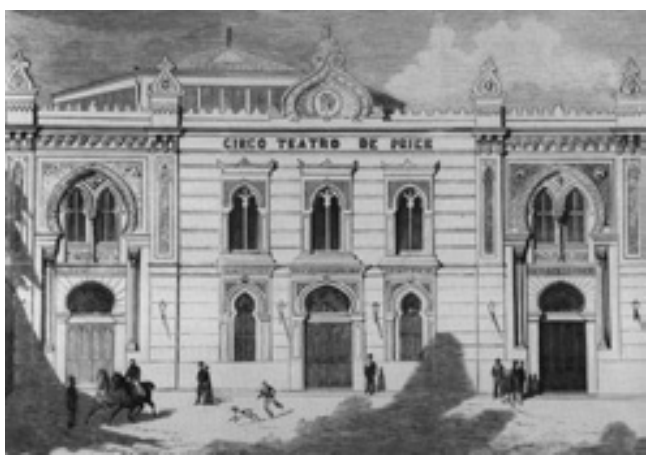

Fig. 1. Exterior del teatro Price. Fuente: Navascués Palacio, Pedro: Arquitectura española (1808-1914). Madrid: Espasa Calpe, 1993. Summa Artis XXXV/2, p. 436.

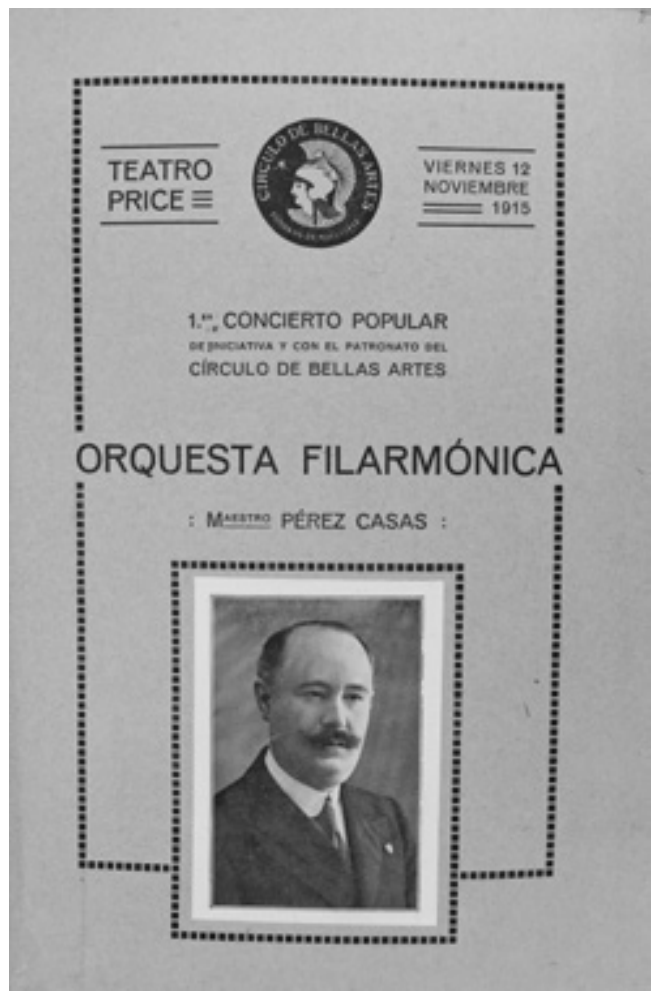

Fig. 3. Bartolomé Pérez Casas. Programa del 12-XI-1915. Archivo del Círculo de Bellas Artes (Madrid).

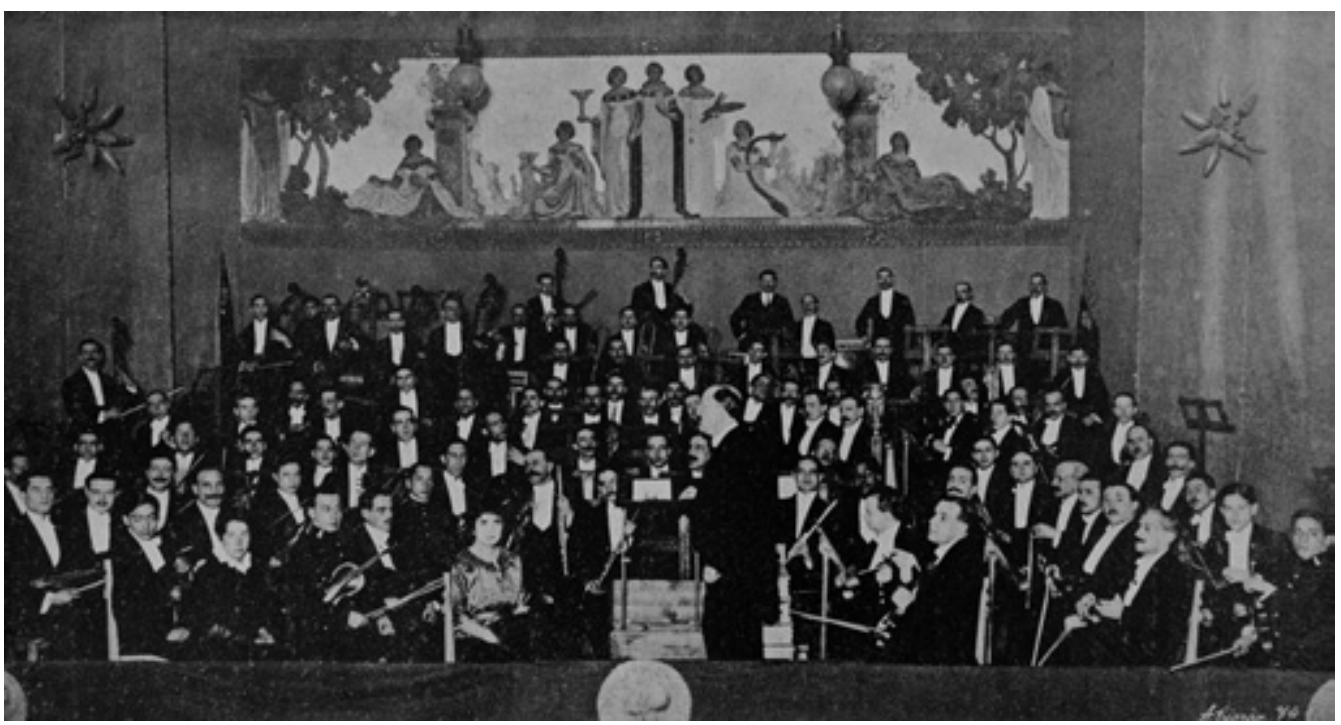

Fig. 2. Orquesta Filarmónica de Madrid (1916). Archivo del Círculo de Bellas Artes (Madrid). 
compositores como los ejecutantes, solicitan del público una atención benevolente que apoye sus nobles esfuerzos los cuales podrían, a veces, convertirse en baldíos por un juicio o una impresión demasiado rápidos. [...]

La Orquesta Filarmónica no puede creer que un plan de cultura consista en la repetición ilimitada de las obras inmortales sino que juzga imprescindible entrar decidida y valientemente en el repertorio moderno en el cual tal vez estén ya las obras de mañana, y no hubiera acometido esa empresa, más llena de dificultades que de lucimiento, si no tuviese la seguridad absoluta de que su público sabe apreciar su esfuerzo, que es el de todos los artistas modernos, por un arte cada vez más grande y más inteligente. ${ }^{15}$

En ausencia de otra documentación ${ }^{16}$, podemos acercarnos a la política del Círculo a través de diversas advertencias y notas que se van intercalando en los programas de mano. Ya hemos citado por extenso la explicación inicial. Al iniciarse la segunda serie de conciertos en enero de 1915, el Círculo expresa su satisfacción por el éxito de la primera, felicita a Bretón como presidente de la Sección de Música, y agradece al público su apoyo y a la Orquesta Sinfónica su participación en el proyecto. Además, ese texto trata de crear un compromiso en cuanto a la producción nacional:

Todos quedamos obligados por este briIlante resultado: el público, a no abandonarnos, disminuyendo su entusiasmo por la obra; nosotros, a mejorarla paulatinamente.

Compenetrados público y Círculo de la misión patriótica que realizamos, puede llegarse al supremo ideal de que en Madrid se den frecuentes conciertos sinfónicos, con programas en los que ocupen puesto preferente autores españoles, antiguos y modernos, contribuyendo de este modo a favorecer el brillante renacimiento musical que comienza a iniciarse, y que debe conducir a la creación definitiva de una escuela propia nacional.
Para este logro proyecta, por su parte, el Círculo, convocar anualmente concursos de obras, a los que puedan presentarse los compositores que empiezan, dando a conocer las premiadas en los conciertos populares que se organicen.

En la segunda serie, que hoy comienza, se ha intercalado alguna de las que alcanzaron premio en el que se celebró en el año 1912. ${ }^{17}$

Más tarde, al presentar la segunda temporada (1915-1916) la entidad patrocinadora explicaría que para cumplir la obra de cultura artística comenzada en diciembre del año anterior había pensado en organizar varias series consecutivas en las que se alternasen las dos sociedades orquestales con que contaba Madrid, la Sinfónica y la Filarmónica. Sin embargo, no lo pudo conseguir debido a la negativa de la primera agrupación. Se decidía en ese momento contar solamente con la segunda:

Queda, pues, encomendada la labor de este año a la Orquesta Filarmónica, la que es bien seguro sabrá lograr del público su incondicional aplauso, poniendo para ello a prueba la profunda laboriosidad, el incansable celo de los ejecutantes, unido al depurado gusto en la elección de obras y al concienzudo estudio de éstas, que ha demostrado el Maestro Pérez Casas. ${ }^{18}$

Aparte de aclarar este importante detalle, el programa volvía a repetir el mismo párrafo del año anterior en cuanto a la compenetración entre el público y el Círculo, la misión patriótica que se estaba realizando y el necesario apoyo a los autores españoles para crear una escuela nacional.

El 10 de noviembre de 1916 da comienzo la tercera temporada y esta vez el Círculo considera consolidado el primero de sus objetivos, dar frecuentes conciertos de música sinfónica, pero quiere desarrollar aún el aspecto patriótico de su proyecto:

Queda por desarrollar en este tercer año de su labor cultural el aspecto patrióti- 
co, también anunciado desde el primer momento, de que en los programas ocupen puesto preferente los autores españoles, antiguos y modernos, contribuyendo así al mayor desarrollo de la música nacional.

A este noble fin tiende el propósito de que en cada concierto de los que se proyectan para esta temporada 1916-17, figure una obra de autor español.

Confía el Círculo, para el logro de este nuevo empeño, en la leal cooperación de los maestros españoles, que seguramente enviarán composiciones adecuadas al intento perseguido; así como, no menos, en el patriótico entusiasmo de la gran masa devota de la buena música, la que, sin duda, se mostrará orgullosa de haber sido parte activa del progreso artístico de la patria. ${ }^{19}$

Si en la primera temporada (1914-1915) se habían interpretado cinco obras sinfónicas españolas en un total de siete conciertos, y en la segunda (1915-1916) se mantuvo ese mismo número en un total de trece conciertos, la tercera temporada (1916-1917) marca, en efecto, un cambio real, ya que da un salto cuantitativo apreciable al presentar doce nuevas obras españolas y repetir otras tres. Llegamos de ese modo a una realidad, rayana en lo milagroso, de incluir una obra española en todos y cada uno de los conciertos. Ese esfuerzo continuaría en la cuarta temporada, que ofreció catorce interpretaciones en catorce conciertos: diez nuevas obras y cuatro repeticiones.

En paralelo a esa exposición intensiva de música sinfónica española, las imágenes fotográficas de trece compositores -Granados, Guridi, Albéniz, Bretón, Chapí, F. de la Viña, Manrique de Lara, Arregui, A. Bretón, Turina, Julio Gómez, Isasi y María Rodrigo - se van a ir sucediendo en la portada de los programas de mano (Figs. 4, 5, 6, 7 y 8).

En la cuarta temporada (1917-1918) el público verá sucesivamente el rostro de otros ocho compositores más y dos intérpretes de idéntica nacionalidad: P. José Antonio de San Sebastián, Chavarri, Pahissa, Sanjuán, P. Blanco, Falla, Lamote de Grignon, Esplá; Costa y Terán.
Esas imágenes subrayan la importancia que a los creadores musicales se les va a conceder en el proyecto patriótico.

A la altura de la cuarta temporada, el Círculo, satisfecho, considera que ha contribuido al renacimiento musical de la capital española. Para consolidar lo ya hecho, declara que seguirá dedicando "un puesto preferente a las nuevas producciones nacionales que ha recibido de Madrid y provincias, repitiendo, hasta incorporarlas al repertorio corriente, todas las estrenadas con aplauso en años anteriores; y proyecta presentar con obras orquestales, a algunos solistas eminentes de que hoy se ufana España". A la vez, la entidad patrocinadora se preocupa por la aceptación de la música extranjera, explicando que quiere cumplir "el propósito de dar a conocer a los autores más en boga, interpretando obras de todas las escuelas, hasta aquellas más avanzadas y aun exóticas, pensando que un público tan culto como el que asiste a estos conciertos está capacitado para conocer las ya aceptadas en todos los programas mundiales" 20 .

Sin abandonar a los compositores, la quinta temporada hará énfasis en los intérpretes, expresando la decisión de invitar a "eminentes solistas nacionales":

Logrado con feliz éxito su cultural intento; conseguido definitivamente que en los programas no se prescinda ya de la obra de autores españoles, acomete en la actual temporada un nuevo y amplio aspecto de estas fiestas de arte: la incorporación en ellas de eminentes solistas nacionales, instrumentistas y cantantes españoles de gran renombre, que en Madrid sólo han sido aplaudidos en la intimidad de audiciones particulares o por limitadas concurrencias en sociedades de arte.

En trámite el contrato de algunos; dependiendo otros del rumbo de la contienda europea, no nos es posible adelantar nombres ni aventurar fechas; prefiere el Círculo limitar su compromiso moral al anuncio del propósito, poniendo su esperanza en el apoyo de toda índole que siempre le prestó la incondicional devoción madrileña. ${ }^{21}$ 


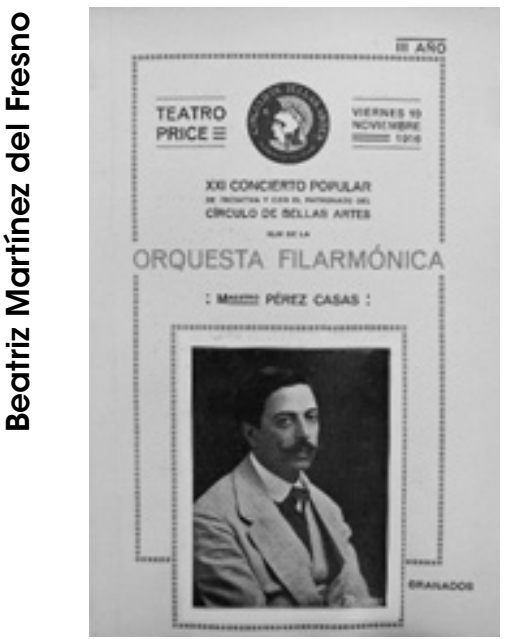

Fig. 4. Enrique Granados. Programa del 10-XI-1916.

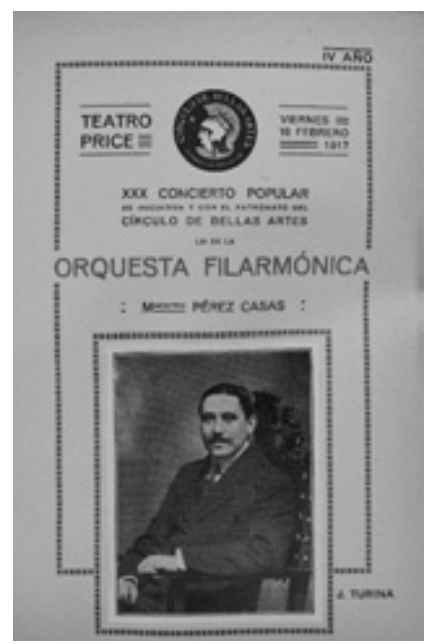

Fig. 7. Joaquín Turina. Programa del 16-II-1917.

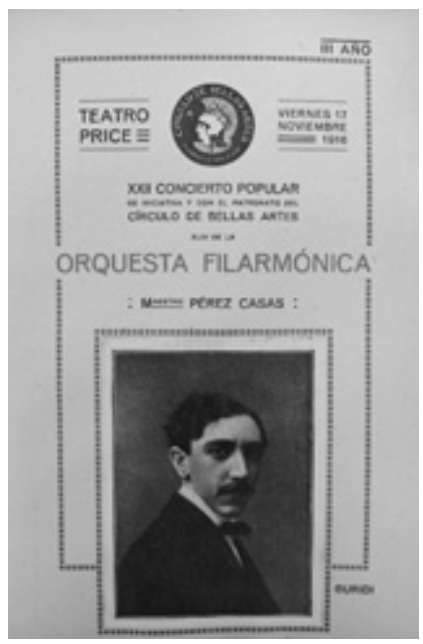

Fig. 5. Jesús Guridi. Programa del 17XI-1916.

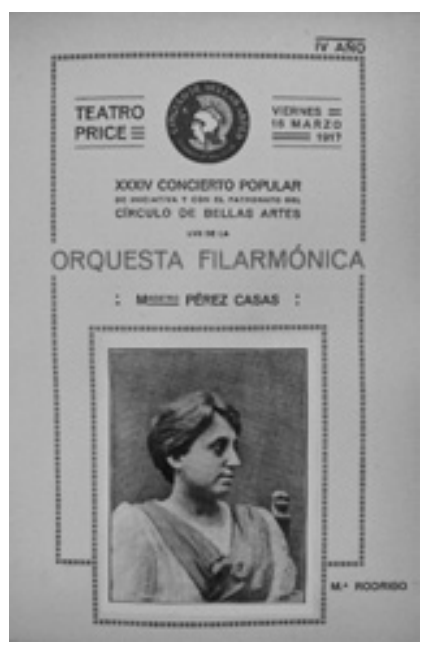

Fig. 8. María Rodrigo. Programa del 16-III-1917.

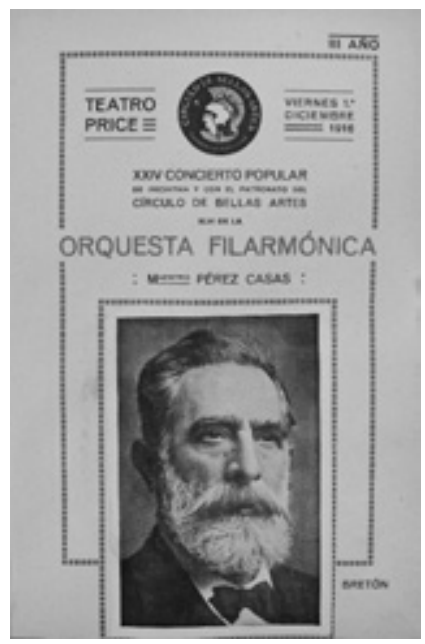

Fig. 6. Tomás Bretón. Programa del 1XII-1916.

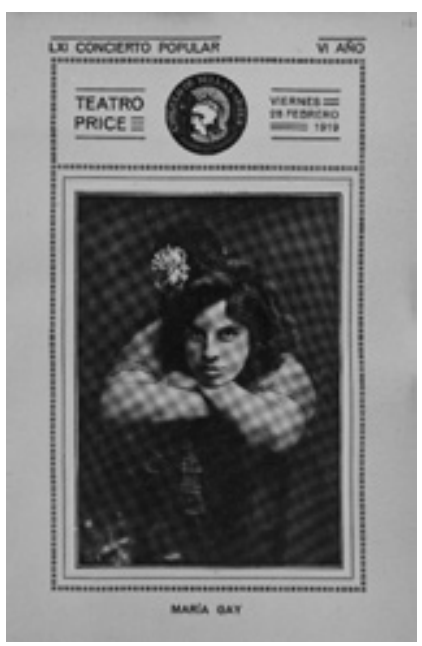

Fig. 9. María Gay. Programa del 28-II1919. 


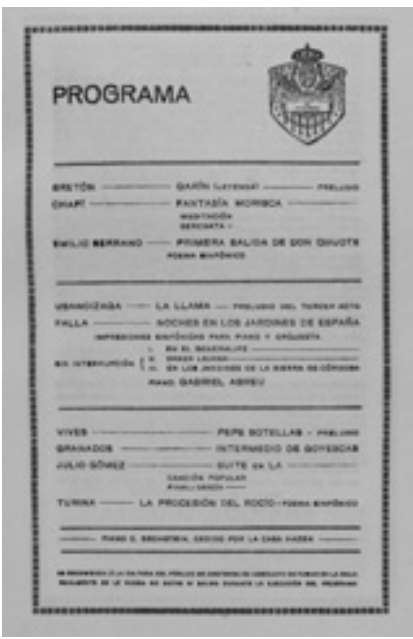

Fig. 10. Programa del 11-III-1921, enteramente dedicado a la música española.

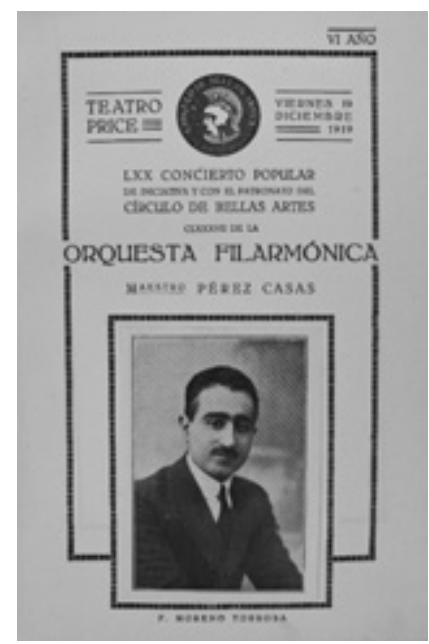

Fig. 13. Federico Moreno Torroba. Programa del 19-XII-1919.

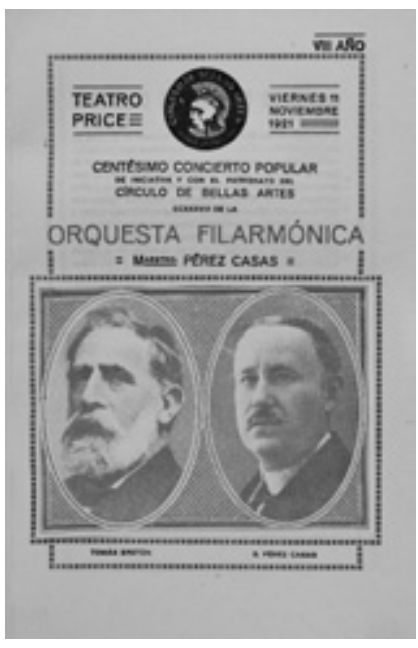

Fig. 11. Centésimo concierto popular. Programa del 11-XI-1921.

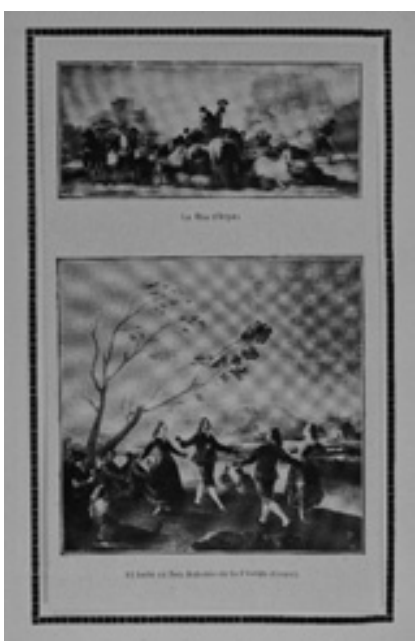

Fig. 14. La Era y El baile en San Antonio de la Florida (Goya). Programa del 19-XII-1919.

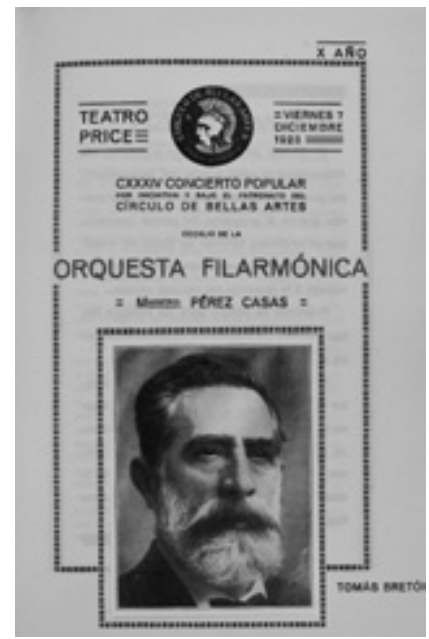

Fig. 12. Concierto dedicado a Tomás Bretón, con motivo de su fallecimiento. Programa del 7-XII-1923.

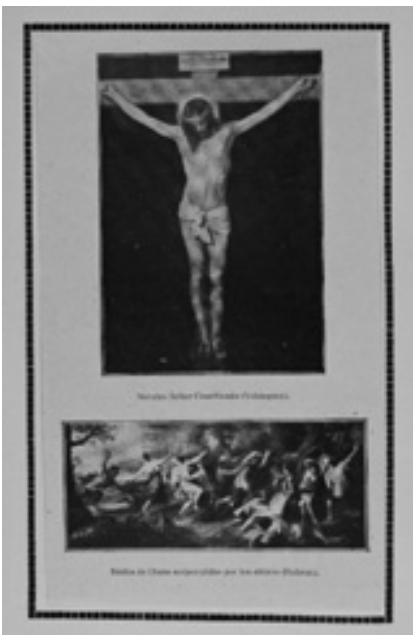

Fig. 15. Nuestro Señor Crucificado (Velázquez) y Ninfas de Diana sorprendidas por los sátiros (Rubens). Programa de 19-XII-1919. 
El repaso de la documentación permite comprobar que, ciertamente, en los conciertos de esa temporada actuaron destacados solistas como G. Cassadó (violonchelo), J. Nin (piano), M. Quiroga (violín), María Gay (canto) y J. Manén (violín), a quienes se unieron en la temporada siguiente (1919-1920) los nombres de P. Casals (violonchelo), A. Fernández Bordas (violín), Leo de Silka (piano), R. Viñes (piano), J. C. Sedano (violín) y el trío Ortiz-Cubiles-Taltavull, que intervino en un Festival Beethoven (Fig. 9).

Finalmente, en la temporada 1920-1921, la sexta, el Círculo ya no considera necesario introducir una nota que explique las líneas de la campaña. Solamente habrá aclaraciones puntuales sobre el motivo por el que se dedica la tercera parte de un concierto a la música española - a petición de numerosos aficionados y por no haber podido ejecutar en su día ese programa preparado en honor de los delegados del Congreso Postal Internacional2 ${ }^{22}$, o la consagración de todo un concierto completo a ocho compositores españoles -Tomás Bretón, Ruperto Chapí, Emilio Serrano, Ramón de Usandizaga, Manuel de Falla, Amadeo Vives, Julio Gómez y Joaquín Turina-, disculpándose en este caso por no haber podido incluir a muchos más autores (Fig. 10). El texto publicado es el siguiente:

Dedicado el concierto de hoy exclusivamente a la interpretación de obras de autores españoles, a solicitud de numerosos aficionados y de gran parte de socios del Círculo de Bellas Artes, la Comisión organizadora de estas fiestas artísticas hace constar que, bien a pesar suyo, no ha sido posible incluir en este programa, por natural imposición de sus proporciones, obras de todos los maestros nacionales contemporáneos, viéndose, pues, obligada a escoger sólo las de algunos de ellos y a tener que renunciar a que se interpreten en la ocasión presente las de otros muchos, no menos ilustres, ya sancionadas por el aplauso público. Y además de tal forzosa limitación, que obliga a ceñirse a las reducidas proporciones de un concierto, la ausencia en éste de determinados autores se debe, en algunos casos, a no haber podido disponerse de momento de los materiales de orquesta correspondientes a sus obras, y en otros a haber aparecido más recientemente sus nombres en nuestros programas [...]. ${ }^{23}$

La celebración del centésimo concierto popular, el 11 de noviembre de 1921, genera una extensa y emotiva reflexión sobre la consolidación de los conciertos populares y su indiscutible éxito se cifra en tres aspectos: la entusiasta acogida del público, el buen hacer de la Orquesta Filarmónica y los méritos personales de Tomás Bretón y de Bartolomé Pérez Casas (Figs. 11 y 12). En ese acto se le entregaban a Bretón las insignias de la Gran Cruz de Alfonso XII costeadas por suscripción popular, por lo que el Círculo le felicita y pide públicamente condecoraciones para el eminente director de la Filarmónica por sus grandes merecimientos.

El Círculo de Bellas Artes, al celebrarse en la tarde de hoy el centésimo de los conciertos sinfónicos que por su iniciativa y bajo su patronato se inauguraron el viernes 4 de diciembre de 1914, quiere expresar aquí, ante todo, su más ferviente gratitud al culto y selectísimo público que a ellos concurre, por la entusiasta acogida y alentador apoyo con que respondió desde el primer momento a la idea inicial e impulsora de estas espléndidas fiestas culturales [...] que, merced al esfuerzo de todos y al favor decidido de la afición madrileña, han llegado a alcanzar el más alto grado como manifestación pública del arte musical en España. El renombre de los Conciertos populares del Círculo de Bellas Artes, traspasó ha mucho las fronteras nacionales [...].

Claro es que si el público respondió tan unánimemente a la feliz iniciativa del Círculo de Bellas Artes al organizar estas fiestas espirituales, fue por la excelencia artística que desde el primer momento revistieron. Cada concierto nuestro es una solemnidad musical, brindada al público con el más altruista y patriótico propósito por parte del Círculo, y el más desinteresado y noble afán de la Orquesta Filarmónica, esa admirable agrupación de entusiastas y generosos artis- 
tas, que sólo persigue los más puros idealismos.

Por ello, el Círculo de Bellas Artes aprovecha la envanecedora conmemoración de hoy para dar una vez más público testimonio de admiración y gratitud a la Orquesta Filarmónica y a los dos preeminentes maestros que dirigen el concierto de esta memorable fecha, ambos ya muy por cima de toda crítica y favor adjetivo.

El maestro Bretón, que dirigió nuestros siete primeros conciertos populares [...], es un venerable patriarca del pentágrama, que traspasó hace ya muchos años los umbrales de la gloria. Y al hacerle entrega en la solemnidad de esta tarde de las insignias de la Gran Cruz de Alfonso XII, adquiridas por suscripción popular, iniciada por el Real Conservatorio de Música y Declamación, de Madrid, unánime y efusivo habrá de ser, ciertamente, vuestro aplauso para el insigne y popular autor de la deliciosísima Verbena de la Paloma.

Como no habrá de ser menos cálido y espontáneo el que otorguéis a Pérez Casas, genuino orgullo asimismo del arte nacional, alma consubstancial de la Orquesta Filarmónica y maestro exquisito, de extraordinaria cultura artística, cuyo concurso se solicita insistentemente fuera de España, y al que como legítimo y bien conquistado galardón honorífico, por su desinterés y abnegada labor al frente de la magnífica orquesta que creó y dirige, y que en tan alto grado contribuye a la elevación de la cultura patria, debiera condecorar igualmente el Gobierno español, dándonos así ocasión propicia para que en breve $y$ ante vosotros mismos, por dictados de estricta justicia, se impusieran aquí al eminente músico, como esta tarde al maestro Bretón, las insignias de la antedicha Gran Cruz, que, de otorgarse por voto popular, hoy mismo, seguramente, lo conferiríais con vuestro preciadísimo colectivo aval y entre entusiastas aplausos. ${ }^{24}$

En los años que restan hasta el límite cronológico que hemos fijado para nuestro estudio ${ }^{25}$, habrá algunos otros programas especiales. Unos porque son dirigidos por Arturo Saco del Valle, por enfermedad del director titular, y otros porque tienen un significado especial, como el concierto dedicado a Tomás Bretón con motivo de su fallecimiento (134. ${ }^{\circ}$ concierto popular, 7 de diciembre de 1923). Finalmente, en diciembre de 1923 se reanuda la práctica de disponer una vez al año un programa compuesto exclusivamente de música española: el $135 .^{\circ}$ concierto popular, celebrado el 14 de diciembre de 1923, se compuso con obras de T. Bretón, E. Halffter, A. Barrios, J. Turina, L. Vega y R. Chapí.

\section{El repertorio sinfónico español}

Una aproximación a los 144 primeros conciertos populares - los efectuados en el teatro Price- nos permitirá sacar algunas conclusiones sobre la forma en que se consolidó el nuevo estilo sinfónico. Sin contar las repeticiones, a lo largo de estos diez años se presentan 85 composiciones de autores españoles ${ }^{26}$, de las que 66 hacen gala de una evidente intención identitaria, visible en el título o en las notas al programa, mientras que, independientemente de su estilo musical o de su sonoridad, las 19 restantes tienen una posición aparentemente neutra en el aspecto nacional ${ }^{27}$.

Estas significativas cifras señalan que más del $75 \%$ de la música española que se interpreta entre 1914 y 1924 remite, de una forma u otra, a los componentes genético-estructurales de la nación española. Trataremos de detallar a continuación cuáles son los elementos implicados, basándonos para ello en el análisis de los programas de mano, paratextos musicales de gran relevancia en el tema que nos ocupa.

\section{Los artistas y sus intenciones}

Como es lógico, las notas al programa aluden siempre al compositor - su fotografía preside a menudo la portada del programa de mano como ya se ha dicho-, y, aunque no lleven firma, suelen exponer algunas consideraciones sobre su obra para facilitar la comprensión del público. Tanto los programas como los comentarios periodísticos muestran el peso que se concedía entonces al aspecto poiético y la reverencia con que público y crítica solía tratar a 
los artistas de las distintas generaciones, vivos y muertos, experimentados o noveles ${ }^{28}$.

Una nota biográfica, de mayor o menor extensión según los casos, indica a los lectores el lugar de origen del creador, un aspecto relevante en aquel contexto. Así puede saber el público de los conciertos populares que una serie de músicos a los que conoce porque viven y trabajan en Madrid proceden en realidad de otros lugares del territorio español: Tomás Bretón es salmantino, Rogelio Villar y José Ramón Blanco-Recio nacieron en León, Joaquín Turina vino al mundo en Sevilla, Bartolomé Pérez Casas es murciano, Teodoro Valdovinos se trasladó desde un pueblo de Huesca, Antonio Paredes nació en Lorca... A veces la nota ubica al autor en una escuela regional: Jaime Pahissa "es uno de los más notables representantes del movimiento musical catalán actual" y Francisco Balaguer "es un joven e inspirado maestro valenciano" 29 .

En ocasiones se menciona la discordancia entre el sentimiento de pertenencia del creador y su lugar de residencia —-Pedro Blanco ha nacido en León pero vive en Oporto, el gallego Andrés Gaos se ha establecido en Buenos Aires- , lo que aporta una cierta tensión emocional, especialmente cuando este es el argumento principal de la obra, tal y como sucede en las dos piezas tituladas Añoranzas, una de Pedro Blanco y la otra de Luis Aula, o en ;Alma española! de María Rodrigo, escrita en Múnich en 1914 y llena "de un sentimiento de recuerdo y de nostalgia de la patria lejana" ${ }^{30}$.

Muy a menudo se declara que la intención del autor es describir a través de la música el paisaje y las escenas tradicionales de su región de origen. Esto sucede al menos en una docena de fragmentos sinfónicos. Pérez Casas quiere ofrecer "la sensación, el ambiente de los paisajes y escenas de la huerta murciana", Villar intenta "traducir musicalmente algunas escenas y danzas campesinas" de León, Albéniz concibe una de sus obras "en un paseo que él y algunos amigos suyos hacían por los alrededores de Barcelona", la pieza de Pahissa es "un canto sano y espontáneo a la tierra natal", Bretón compone un poema sinfónico "a modo de homenaje [...] a su ciudad nativa", López Chavarri presen- ta diferentes momentos de la vida popular de su región y Facundo de la Viña quiere, en Covadonga, "cantar a su tierra natal" 31.

Sin embargo, también hay fragmentos en los que el compositor no se identifica con su región de origen, sino con otra que ha conocido después y que admira o recrea. Es el caso de las famosas Escenas andaluzas de Bretón y del poema Sierra de Gredos en el que Facundo de la Viña, un asturiano afincado en Valladolid y luego en Madrid, ofrece al público "las sensaciones experimentadas por el autor al contemplar la sierra castellana"32. También entra dentro de esta tipología la Granada que describe el coruñés Andrés Gaos o la Égloga de BlancoRecio, que, habiendo nacido en Burgos y residiendo en Madrid, "quiere dar una exacta sensación de sus ideas, impregnado del ambiente de melancolía que se respira en las regiones vascas, donde pasa parte del año"33. Por su parte, Benito García de la Parra, natural de Toledo, se propone "trasladar al pentágrama el aroma, denso y penetrante, del canto popular que él gustó en las tierras de Galicia" ${ }^{34}$.

Algunas de las obras parecen haber surgido de una tarea recolectora desarrollada con constancia: "desde su retiro, en el colegio de capuchinos de Lecároz (Navarra), el joven padre José Antonio se dedica a coleccionar cantos populares de su región y a revestirlos de un suave ropaje armónico" ${ }^{35}$; de esa labor nacen las dos series de preludios vascos del que hoy conocemos como padre Donostia. En otro programa leemos que la personalidad de Jesús Aroca, autor de Arrabales castellanos, "se destaca vigorosamente entre aquellos de nuestros jóvenes que consagran sus desvelos al estudio de nuestra música popular, llevados de la elevada orientación artística de nuestra nacionalización musical" ${ }^{36}$.

Como segunda opción, los compositores no se referirán al paisaje o a las costumbres tradicionales de la región, sino a productos culturales, imágenes, personajes o ficciones elaboradas previamente por otros artistas. La contemplación de Las hilanderas, obra maestra de Velázquez, produce en la sensibilidad de Rogelio Villar "un efecto que engendra la idea musical que ha de ser tratada sinfónicamente" y el compositor afirma que quiere "revelar ese pa- 
ralelismo de sensaciones, sumiéndose en un estado emocional análogo a aquel en que el pintor debió hallarse al concebir y ejecutar su creación" ${ }^{37}$. Por su parte, Federico Moreno Torroba se inspirará en cuatro pinturas de Goya, Velázquez y Rubens, que excepcionalmente se reproducen en el programa de mano ${ }^{38}$ (Figs. 13, 14 y 15).

En la misma línea de inspiración en un producto cultural previo, la lectura del Quijote dará lugar a tres creaciones presentadas en los conciertos populares: Los galeotes de Bretón, Una aventura de don Quijote de Guridi y La primera salida de don Quijote de Emilio Serrano. En el primer caso, las notas aclaran que el poema sinfónico de Bretón, escrito en "brevísimo tiempo" para el concurso convocado en el centenario de 1905, solo pretende ilustrar "uno de sus infinitos pasajes que por su fuerza evocativa inspiran en el músico el deseo de un comentario" ${ }^{\prime 39}$. En el segundo ejemplo, Guridi selecciona con criterio sentimental el episodio en que el caballero lucha contra el gallardo vizcaíno (capítulos 8 y 9 de la novela cervantina), lo que le dará pie a intercalar un tema popular vasco, una decisión que sin duda tiene que ver con el hecho de que el autor sea alavés de nacimiento y bilbaíno de adopción ${ }^{40}$.

Aunque todas las obras sinfónicas a las que nos referimos carecen de texto, hay en los comentarios frecuentes alusiones literarias. Eduardo López Chavarri traza sus Valencianas a partir de los fragmentos poéticos de Teodoro Llorente (Fig. 16); en sus Danzas fantásticas Joaquín Turina copia los epígrafes de una novela de José Más; Facundo de la Viña hace una ofrenda espiritual a José María Gabriel y Galán; las notas de Los gnomos de la Alhambra de Chapí reproducen fragmentos del poema Granada de José Zorrilla; Kasida de Conrado del Campo incluye un texto de Tomás Borrás; y el Atardecer andaluz de Antonio Paredes se inspira en una escena de los hermanos Quintero. Encontramos incluso una Dolora sinfónica, trasunto del género poético cultivado por Ramón de Campoamor.

\section{Lugares y tiempos. El paisaje}

Tal y como se ha dicho, en el repertorio de los conciertos populares es frecuente que los títulos de las obras y las notas al programa doten a la música de una potencial significación territorial ${ }^{41}$. Esta dimensión puede coincidir con una ciudad, una provincia, una región o todo un país visto desde fuera. Obviamente, los recursos musicales utilizados incidirán en la descripción de lo local, en lo característico y en lo pintoresco.

Si admitimos que el código descriptivo funciona, hemos de suponer que la música orquestal del teatro Price tenía la capacidad de transportar al oyente a espacios naturales, abiertos y despoblados o accidentados y montañosos. En esa ficción se mueven las expectativas de la época, ya que los compositores se permiten describir con detalle la "llanura desolada" de Los galeotes, los "floridos valles" y los "imponentes riscos" de la Sierra de Gredos, la "serena calma de la Naturaleza" que envuelve a Jimena y Rodrigo, y todo lo que se divisa desde la ladera del Pirineo vasco ${ }^{42}$.

Dentro del abanico temático que estas obras presentan cabe destacar la recurrencia al modelo de la égloga. En parajes naturales poco poblados aparece algún pastorcillo, a menudo enamorado, como contrapunto humano de la escena. Véase como ejemplo el comentario de la evocación sinfónica Sierra de Gredos de Facundo de la Viña:

Los floridos valles donde los pastores bailan al ritmo del tamboril, recordando en sus canciones al caudillo Almanzor, nombre que tiene la montaña más alta; las lagunas llenas de misteriosas leyendas; los imponentes riscos y la paz que en aquellas alturas se siente, es lo que ha inspirado esta obra hondamente sentida. ${ }^{43}$

Por su parte, la descripción de la Égloga de José Ramón Blanco-Recio comienza cuando "en una alta ladera del Pirineo vasco, a la margen de un espeso hayedo, reposa el pastor mientras sus ovejas esparcidas semejan blancos vellones prendidos en la verde inmensidad". Ese pastor contempla la naturaleza y el pueblecillo donde vive "la que le dio su amor, contrariado por sus padres". Con su caramillo se lamenta en dolorosas notas. En sueños ve a su 
amada que asiste con todo el pueblo a la procesión de la Virgen Milagrosa en la ermita cercana, y después a un baile acompañado por el chistu y el tamboril. Finalmente, al despertar de su bello sueño, el pastor regresa a su soledad en la inmensidad de la montaña ${ }^{44}$.

Una tercera variación del mismo argumento es presentada por Teodoro Valdovinos, pero en esta ocasión el amor imposible es sustituido por la resistencia del pastor a las tentaciones mundanas:

En la paz campestre y entre las montañas rocosas, un joven pastorcillo de égloga se entretiene en construir flautas de caña, de esas toscas y primitivas, cuyos sonidos en plena naturaleza armonizan con el paisaje. Una bella dama aparece y platica con el pastorcillo, encomiándole las excelencias de la vida mundana, siempre divertida y pródiga en refinamientos, instándole a que abandone la vida aldeana. Él vacila al subyugarle la belleza de ella, y en su alma ingenua aparece la pasión brevemente, hasta que su entusiasmo va disipándose al vislumbrar por su instinto de hombre aldeano un capricho de frivolidad femenil. El pastorcillo rechaza las sugestiones placenteras de la bella aparecida; los refinamientos mundanos son efímeros; él seguirá en su ambiente tranquilo y saludable, ante el sol y las ventiscas, entre montañas. ${ }^{45}$

Este tipo de égloga pastoril, elogio poético de una serena vida montañesa, se troca en "escena geórgica" en la evocación Por tierras de Castilla. Como pretexto para ello, su autor, nuevamente Facundo de la Viña, se refiere a un viaje desde Béjar hasta Barco de Ávila en una tarde de agosto. En un recodo del camino el viajero se topa con una fiesta campesina que le envuelve en cantares y bailes. Después, cuando los aldeanos entran devotamente en el santuario, el viajero se abandona a sus emociones líricas frente a la "sinfonía del paisaje" y los campos cultivados, sentidos a través de los versos de El ama de Gabriel y Galán que, para mayor claridad, reproduce el programa de mano.

Junto a los cantos al paisaje, encontraremos a menudo un discurso sonoro que remite a un entorno natural tamizado por la actividad social, como sucede en las descripciones de la huerta murciana o en las escenas campesinas de León. También figuran los jardines como marco de estos pintorescos cuadros. En ellos se sitúa la acción de La leyenda de Santa Casilda ${ }^{46}$ y a los jardines se referirá también la primera obra de Falla ${ }^{47}$, que en uno de sus números nos transporta al Generalife (Figs. 17 y 18). La Alhambra, lugar de memoria emblemático, aparece de nuevo en otras dos piezas de Chapí y Gaos, mientras Giménez tomará La torre del Oro sevillana como pretexto para su escritura andalucista.

Más raramente se definen espacios interiores, que pueden ser explícitos o implícitos. Entre los primeros, prácticamente el único escenario cerrado, y no del todo, es la barraca valenciana en la que según López Chavarri una madre adormece a su pequeño. Entre los segundos, cabe mencionar el Museo del Prado, el lugar en el que implícitamente es posible contemplar Las hilanderas en compañía de Rogelio Villar o los cuadros de Velázquez, Rubens y Goya que inspiraron a Moreno Torroba (Figs. 19 y 20).

Si nos fijamos ahora en otra dimensión, repararemos en que las escenas o las impresiones suceden en un momento determinado, que puede ser tanto contemporáneo como histórico. A veces ese marco temporal es señalado de una forma sorprendentemente precisa y a ciertos cuadros se les viene a señalar un mes concreto - junio, agosto- y con frecuencia una hora del día - la madrugada, la mañana, el atardecer o la noche- - Los comentarios incluyen detalles sobre la luz que ilumina esas imaginarias escenas. Luces y sombras, aromas y sensaciones acompañan muchas descripciones ambientales.

Otro tipo de viaje en el tiempo es de carácter autobiográfico, en este caso hacia los recuerdos de juventud. Tomás Bretón escribe Elegía y añoranzas en memoria de su esposa y el viaje en el tiempo se produce a través de la autocita. En sus notas explica lo siguiente:

Comienza la obra en suaves sonoridades de la cuerda con sordina; después la madera canta los tristes acentos de la Elegía. No 
tardará en escucharse el tema que servía de base a la escena final de Los amantes de Teruel, precisando el patético ambiente de la obra. Luego surgen nuevos aspectos, y entre el tejido sinfónico se deslizan algunos recuerdos de La verbena de la Paloma, imprecisos, pero sin embargo claramente evocativos, lo mismo que cuando más lejos son los ritmos y armonías de la Jota de La Dolores lo que se escucha. Posteriormente, sombrías sonoridades conducen a un ritmo de marcha fúnebre, base sobre la cual se reproduce el tono elegíaco del comienzo. Sombra y tristeza se apoderan del ambiente; los contornos se hacen cada vez más confusos e imprecisos; toda idea se esfuma, se disuelve, desaparece, en fin. ${ }^{48}$

La proyección autobiográfica puede ser también indirecta si no es el compositor quien efectúa la rememoración virtual sino un personaje abstracto, como "el ausente" en la obra de Luis Aula o "el artista" ya citado en la de María Rodrigo. Veamos el comentario del primero:

Alejado de su patria, el ausente la recuerda en sus ensueños. Primeramente acude a su memoria la inquieta juventud, el primer amor, y el recuerdo de estos sentimientos le produce la nostalgia de exaltadas pasiones pretéritas. Después, al recordar una vieja canción de su país, que evoca en su espiritu momentos de infinita ternura, una gran melancolía le invade, pero la domina auxiliado por los primeros recuerdos, que de nuevo le asaltan, dando un nuevo sentido esperanzado y optimista a la canción, cuyo recuerdo le ha traído el de la patria lejana. ${ }^{49}$

Finalmente, algunas músicas tradicionales tienen de por sí una dimensión temporal implícita ya que, dada su pervivencia a lo largo de los siglos, la carga histórica se proyecta sobre ellas. De ese modo, al escuchar la suite murciana se ha de percibir la "tan fuerte influencia árabe" de las tradiciones y fiestas de la región que señala Pérez Casas" ${ }^{50}$ y al oír la "antigua melodía oriental" utilizada en la Suite en La, se pensará "que por su tonalidad y especial fisonomía, bien pudiera ser de las importadas por los israelitas españoles", tal y como sugiere Julio Gómez ${ }^{51}$ (Figs. 21 y 22).

\section{Escenas populares}

Podríamos decir que la aspiración común a la mayoría de estos artistas es hacer música española, una música que adquiera su significación en relación con los elementos característicos o con los imaginarios de la nación. El amor o el respeto a la patria se da por supuesto, pero, como se verá, en la mayoría de los casos la sensación de pertenencia se va a expresar desde el apego a lo local y la identidad con la región. La nostalgia o la añoranza aparecen con frecuencia en títulos y explicaciones, cuando no la melancolía que, se dice, producen ciertas tierras.

Obras sinfónicas, a menudo subtituladas "impresión", "escena", "cuadro" o "boceto", ensalzan la vida campesina y hacen añorar no solo un lugar de origen, las vivencias concretas, sino también la placidez de un sistema de vida perdido que aparece idealizado. Quizá como una señal de resistencia al cambio ${ }^{52}$, los símbolos de la colectividad rural, la fiesta y la romería, van a ser una parte importante de la descripción, mientras que la danza tradicional servirá casi siempre como vehículo para la alegría y el movimiento.

Entre otras muchas celebraciones populares, citamos, por ejemplo, la "fiesta de alegría y bullicio" que tiene lugar en la huerta murciana, las "fiestas provincianas" y la "sana y robusta alegría popular" mencionadas en jAlma española!, los "ecos de la romería lejana" y el "bullicio de la fiesta" de uno de los preludios vascos del padre San Sebastián, los "rumores de las gentes en fiesta" que acompañan el primer cuadro levantino de López Chavarri, los "acentos de fiesta" que resuenan en la Granada de Gaos, en la aldea gallega de Benito García de la Parra y en el segundo cuadro castellano de Moreno Torroba ${ }^{53}$.

Y si son verdaderamente abundantes las fiestas y romerías, más aún lo serán las danzas. Abelardo Bretón convierte en baile el tercer movimiento de su Fantasía gitana; una "animada danza" cierra la Suite en La de Julio Gómez; 


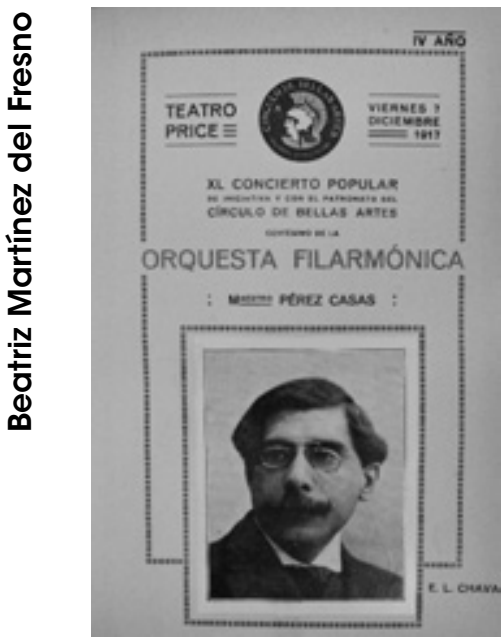

Fig. 16. Eduardo López Chavarri. Programa del 7-XII-1917.

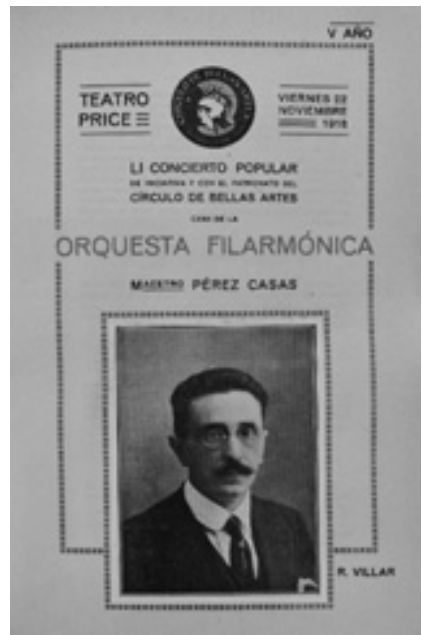

Fig. 19. Rogelio Villar. Programa del 22-XI-1918.

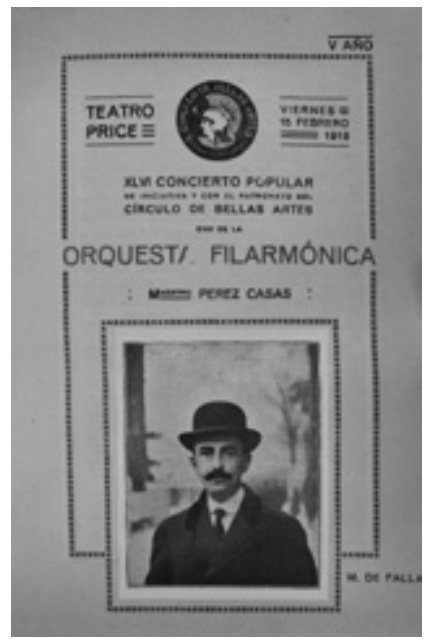

Fig. 17. Manuel de Falla. Programa del 15-II-1918.

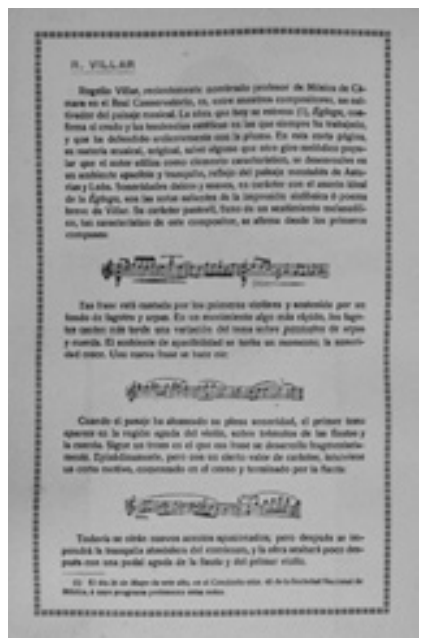

Fig. 20. Notas sobre Égloga, de Rogelio Villar. Programa del 22-XI-1918.

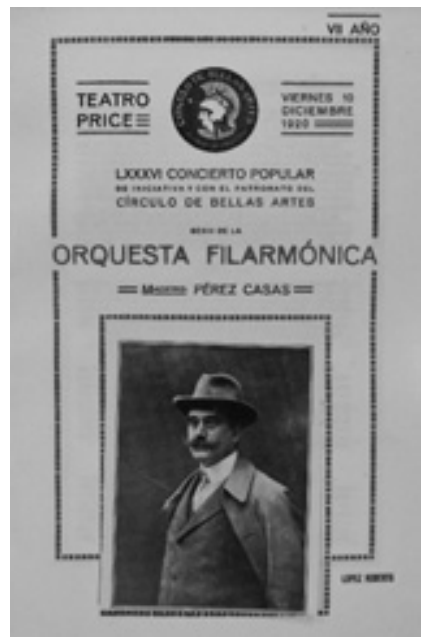

Fig. 18. Mauricio López Roberts. Programa del 10-XII-1920. 


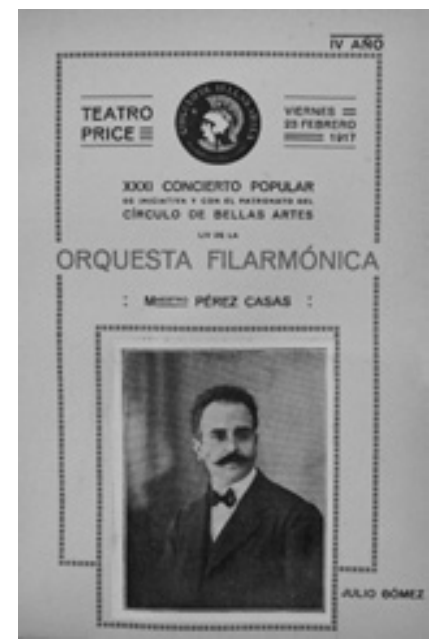

Fig. 21. Julio Gómez. Programa del 23॥-1917.

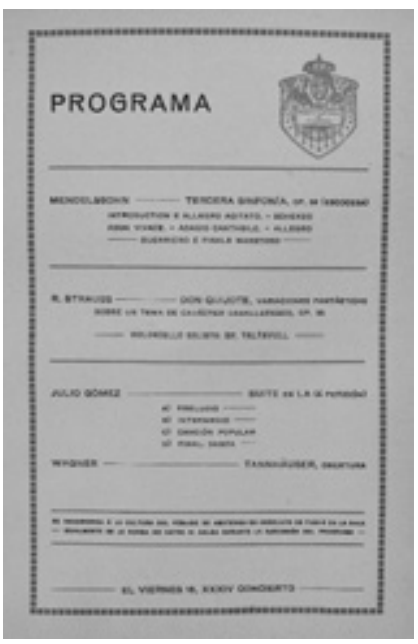

Fig. 22. Programa del 9-III-1917, en el que se interpreta la Suite en La a petición popular.

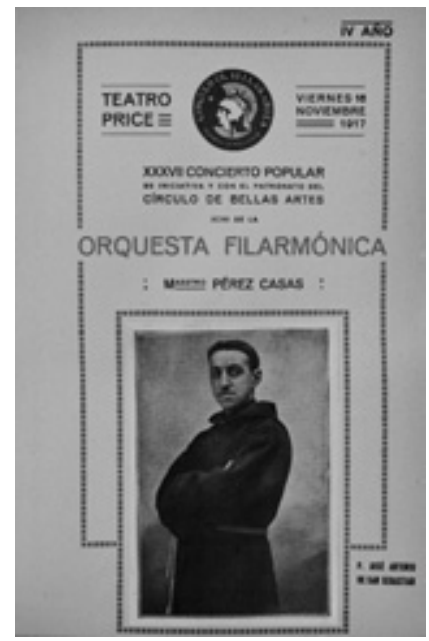

Fig. 24. Padre José Antonio de San Sebastián. Programa del 16-XI-1917.

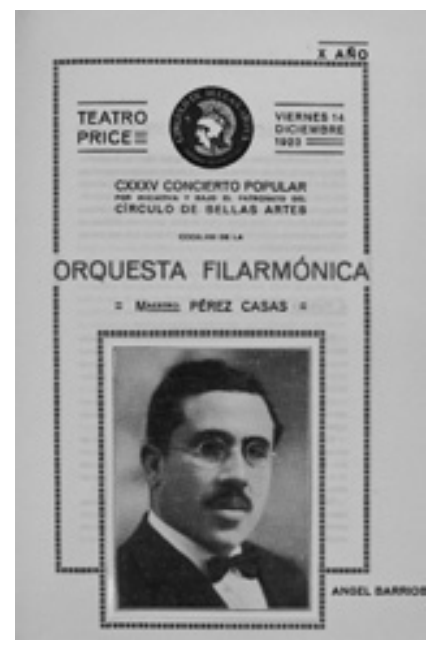

Fig. 23. Ángel Barrios. Programa del 14-XII-1923.

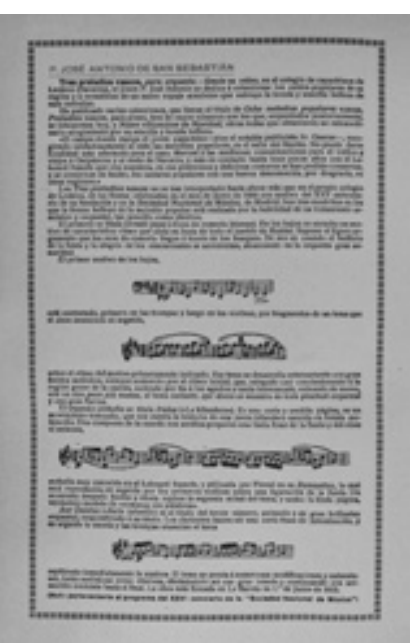

Fig. 25. Notas sobre Tres preludios vascos, del padre José Antonio de San Sebastián. Programa del 16-XI-1917.

* Todos los programas reproducidos (Figs. 4-25), proceden del Archivo del Círculo de Bellas Artes (Madrid). 
el tercer preludio vasco es un "Baile infantil"; el segundo cuadro levantino presenta "Les dansaes de la Vall de Albaida" y el cuarto alude a la danza de los Nanos; uno de los nocturnos de Falla se titula "Danza lejana"; la aldea castellana estalla en una "risueña orgía de cantares y bailes"; en el Pirineo vasco "bailan las engalanadas parejas con creciente ardor"; la suite de El sombrero de tres picos remite a la seguidilla, la farruca y la jota; Ángel Barrios describe una zambra en el Albaicín (Fig. 23); y Turina hace oír en su Sinfonía sevillana el schottis madrileño, el zapateado y el garrotín ${ }^{54}$.

En este aspecto no siempre se trata de bailes procedentes de la tradición popular española, ya que también encontramos recreaciones libres de otros tipos de danza, como la interpretada por las esclavas moras de Casilda, el baile goyesco de San Antonio de la Florida o las de la época de Pepe Botellas - tarantela, minuetto y galop - que Vives reinventa a partir de sus estereotipos. Por otra parte, dos piezas de Tomás Bretón, escritas respectivamente en 1887 y 1909, se arraigan en la escuela bolera clásica, tal y como indican sus títulos, Panaderos y Bolero ${ }^{55}$.

En cualquier caso, tanto se prodigaron en el repertorio de la época las "bulliciosas" fiestas populares y las "animadas" danzas, que la nota sobre Noches en los jardines de España, con evidente intención de diferenciar la obra de Falla respecto a ese telón de fondo, viene a señalar que sus nocturnos no pretenden ser descriptivos sino expresivos, añadiendo: "algo más que rumores de fiestas y de danzas ha inspirado estas evocaciones sonoras, en las que el dolor y el misterio tienen también su parte" ${ }^{\prime 56}$.

Algunas procesiones $u$ otros ritos de devoción popular constituyen el complemento de muchas fiestas y romerías. Los personajes o las celebraciones de este tipo son ilustrados con melodías "de carácter religioso", que aparecen, por ejemplo, en relación con los dos frailes de la orden de San Benito que encuentra don Quijote; en la Procesión del Rocío en Sevilla; acompañando el cortejo de boda que conduce a los novios a la iglesia en el valle de Baztán; en la devota comitiva que se dirige a una ermita castellana; cuando se celebra la procesión de la Vir- gen Milagrosa en un pequeño pueblo del Pirineo vasco; o representando el santuario de Covadonga $^{57}$.

\section{El regionalismo y sus recursos musicales}

El repertorio sinfónico español de los conciertos populares recurre frecuentemente a los elementos característicos de la cultura tradicional, aunque los extraiga de su contexto, los represente o los recree. Además, los títulos y los temas dirigen a menudo la atención del oyente hacia una región en particular, lo que nos permite clasificar sin dificultad por regiones unas 35 obras, más de la mitad del repertorio estudiado.

En sentido decreciente, empezaremos la enumeración por las doce piezas que se refieren a Andalucía, en las que encontramos tanto planteamientos costumbristas como fantásticos, unos actuales y otros alejados en el tiempo. Por su orden de presentación en los conciertos, son las siguientes: Escenas andaluzas (Bretón), Los gnomos de la Alhambra (Chapí), La procesión del Rocío (Turina), Noches en los jardines de España (Falla), Granada, un atardecer en la Alhambra (Gaos), Córdoba (Albéniz), La torre del Oro (Giménez), Kasida (Del Campo), Boceto andaluz para violín y orquesta (García Morales) Atardecer andaluz (Paredes), Impresiones de Granada-Zambra en el Albaicín (Barrios) y Sinfonía sevillana (Turina).

Otras seis piezas se adscriben al País Vasco y Navarra: Tres preludios vascos y Cuatro preludios vascos (padre San Sebastián), Égloga (Blanco-Recio), Campesina (Sanjuán), Suite de Amaya (Guridi) y Melodía religiosa sobre un tema popular vasco (Arregui) (Figs. 24 y 25).

León y Castilla la Vieja agrupan cinco obras sinfónicas: Escenas populares (Villar), Salamanca (Bretón), Sierra de Gredos y Por tierras de Castilla (F. de la Viña) y Égloga (Villar). Otros tantos fragmentos remiten a Castilla la Nueva, sea a través de la novela cervantina (Los galeotes, Una aventura de don Quijote, La primera salida de don Quijote, de Bretón, Guridi y Serrano respectivamente) o independientemente de ella: Cuadros castellanos (Moreno Torroba) y Rapsodias de la Mancha (Vega).

Al país catalán se refieren Catalonia de Albéniz y Obertura sobre un tema popular catalán 
de Pahissa, y a Levante, Valenciana de López Chavarri y El poble está en festa de Balaguer. Solo una vez se canta a Murcia ( $A$ mi tierra de Pérez Casas), otra a Galicia (Tríptico gallego de García de la Parra) y una tercera a Asturias (Covadonga de F. de la Viña).

El reparto geográfico es desigual y, como se puede notar, quedan fuera de este mapa sonoro Aragón (solo implicado en la Jota de La Dolores), Extremadura, Baleares y Canarias. Seguramente procede indicar aquí que, independientemente del número de compositores de cada región que hubieran ofrecido espontáneamente sus partituras al Círculo o a la Filarmónica, es cierto que las giras anuales de la orquesta propiciaban los estrenos de los compositores en su propia ciudad y, en ese sentido, es importante saber que hasta muchos años más tarde la orquesta no actuó en Extremadura ni en Baleares.

Pensando en los años del 98 ha escrito Mainer que "toda España es región, fragmento, como si en los momentos de crisis de identidad que corren fuera difícil concebirla como totalidad" $^{58}$. Desde luego, esa fragmentación domina en la imagen musical de España, que años más tarde sigue recurriendo al folclore regional, un procedimiento criticado por el sector europeísta de la crítica ${ }^{59}$.

El recurso empleado con mayor frecuencia a la hora de describir estos cuadros o escenas regionales consiste en citar de manera literal las melodías populares pertenecientes a su ámbito o asociadas a las acciones que se quieren evocar. De hecho, las notas al programa tienden a identificar las melodías utilizadas en al menos veinte obras, a veces de una forma genérica y otras muy precisa. Así, igual que en su momento lo supo el público del teatro Price, podemos saber también nosotros que en iA mi tierra! se citan seguidillas murcianas, coplas, cantos de trabajo y un romance morisco; las canciones "El pobre payés" y "La filadora" aparecen en CataIonia; un tema de muelo, otro de arada y la charrada titulada "El burro de Villarino" figuran en Salamanca; una serie de melodías populares extraídas del valle de Baztán, donde, según Gascue, el aislamiento había favorecido la conservación de valiosos materiales sonoros, se citan en Tres preludios vascos y Cuatro preludios vas$\cos ^{60}$; un tema montañés, la danza "Les dansaes de la Vall de Albaida", una canción de cuna y "Lo ball de'Is Nanos" forman parte de Valencianas; la muñeira está en el Tríptico gallego; una folía, una canción de cuna, la canción del hogar y una seguidilla manchega suenan en Rapsodias de la Mancha ${ }^{61}$.

Entre las obras andaluzas, una de las descritas con mayor precisión es La procesión del Rocío, donde Turina introduce las seguidillas y las soleares, para terminar con la Marcha Real y el repique de campanas:

Triana en fiesta. Comienza con unas seguidillas, y después, sobre un pianísimo, una breve copla de soleares que canta la viola. Desarróllanse entrelazados estos temas, un momento interrumpidos por un brevísimo episodio en el ritmo de garrotín que entona un borracho. Cuando la seguidilla alcanza plenitud sonora es interrumpida por la llegada de la Procesión. Escúchase la pintoresca melodía que en la flauta toca el tamborilero y que él mismo se acompaña, y aparece el tema religioso de la Procesión, que iniciado en los violonchelos, va reapareciendo sucesivamente y cada vez con mayor sonoridad entre los diversos apuntes de los temas populares del primer período. La Procesión avanza, y entonces aparece el tema religioso en todo su triunfal esplendor, acompañado característicamente por los acentos de la Marcha Real y por el repique de las campanas. De nuevo resuenan las danzas y canciones de la animada fiesta, y todo, al fin, se extingue poco a poco. ${ }^{62}$

Otras veces las notas precisan que la manera de crear ambiente rústico, característico o regional, no depende de la cita de melodías recogidas de la tradición oral o tomadas de un cancionero. En ese sentido, una segunda opción es crear dentro de las pautas populares, tal y como se afirma que ha hecho Pedro Blanco ${ }^{63}$. La estilización es un concepto muy querido por Manuel de Falla y los críticos que le ensalzaron en la Edad de Plata ${ }^{64}$. Aunque hoy sepamos que el compositor gaditano utilizó la música popular 
en mayor medida de lo que entonces se decía, en las notas de las Noches en los jardines de España su procedimiento aparece explicado de esta manera:

La parte temática de esta obra está basada (como en la mayor parte de las de su autor, La vida breve, El amor brujo, etc.) en los ritmos, modalidades, cadencias y figuras ornamentales que caracterizan el canto popular andaluz, que, sin embargo, muy pocas veces se aplica en su forma auténtica; y el mismo trabajo instrumental estiliza frecuentemente determinados efectos peculiares a los instrumentos del pueblo. ${ }^{65}$

De todos modos, para lograr el deseado sabor regional no era imprescindible incrustar las melodías tradicionales con todos sus ingredientes en el tejido sinfónico. También se utilizaba a menudo el recurso de evocar solamente los ritmos de ciertos cantos y danzas o los timbres de los instrumentos populares. En ese sentido, la guitarra es asociada a los ambientes murcianos o andaluces; la flauta y el tamboril aparecen en la procesión sevillana; el tabalet, la donçaina y la cobla son evocados en los cuadros levantinos; el chistu y el tamboril, en la égloga pirenaica. La sonoridad del órgano sirve para aludir al ambiente devoto mientras las del caramillo o la flauta de caña dan los deseados toques pastoriles a las églogas.

\section{Individuo y colectividad. Motivos heroicos e históricos}

El paisaje o las escenas campesinas se complementan a menudo con figuras individuales y colectivas. La alusión a elementos escénicos imaginarios es fácilmente comprensible en el caso de los fragmentos sinfónicos procedentes de obras teatrales ${ }^{66}$. Sin embargo, la aparición de personajes resulta más sorprendente en las piezas que han sido pensadas directamente como músicas de concierto, aunque sepamos que algunas de ellas se derivan de la tradición del poema sinfónico — se subtitulan de ese modo ocho obras ${ }^{67}$ - y otras se ubiquen en la estela de la inspiración pictórica o literaria al uso, que da lugar a "cuadros", "escenas", "bocetos", "impresiones" o "evocaciones" sinfónicas.
En la narrativa textual, y en su contraparte musical, hay a menudo un protagonista masculino, sea pastor, viajero, artista (Velázquez, Bretón, "el artista") o simplemente un "ausente", que se enfrenta o se relaciona con la naturaleza, el amor imposible, las tentaciones mundanas, el éxito profesional o la pertenencia nacional. También encontramos figuras cargadas de simbolismos religiosos, históricos o culturales cuando se alude a Jesucristo, al Cid, a don Quijote, a José Bonaparte o a la guerra de Cuba. Muchos de estos temas están cargados de valor identitario, a través de la religión, de la literatura, de la construcción heroica de la nación y de la reivindicación emotiva del patriotismo en las guerras. El recurso al obstáculo se hace especialmente patente en las aventuras quijotescas, que representan siempre un ideal imposible y una lucha fallida.

Algunas de estas figuras individuales tienen su contraparte femenina, sea en forma de pareja - -Jimena y Rodrigo, Bretón y su esposa, don Quijote y Dulcinea o "los novios" de forma abstracta- o en una relación paterno-filial, tal es el caso del Rey moro y su hija Casilda. Entre las figuras femeninas, encontramos, como de costumbre, a la madre en el nivel humano y doméstico y a la Virgen en el plano religioso. Los niños aparecen solo ocasionalmente, bien en un baile infantil, bien en relación con las canciones de cuna.

Muchos de los individuos aparecen integrados en un grupo o rodeados de cortejos, por lo que esclavas, galeotes, hilanderas, majos, gnomos, hadas, mozos y romeros cumplen en el relato de estas obras sinfónicas un papel similar al del coro en la ópera o al del cuerpo de baile en la danza escénica.

Las escenas colectivas se justifican en relación con el trabajo (en la huerta o en la era, a través de acciones como la trilla, el arado o el muelo), la celebración de un rito social (boda) o religioso (procesiones), la fiesta y la diversión (romerías, danzas). Hay que decir que así como los individuos viven emociones diversas (la nostalgia, la tristeza, el dolor, la ternura, el amor...), salvo en el caso de los quejosos cautivos cristianos de Toledo y de los galeotes cervantinos, los grupos suelen ser alegres y bulliciosos, incluso cuando los forman seres fantásticos como los gnomos y las hadas. 
Ciertos personajes pintorescos dan pie a la introducción del humor y la sátira. Es el caso del borracho que "canta" en La procesión del Rocío y el de las mozas "del partido" en La primera salida de don Quijote. Excepcionalmente encontramos animales: en el Rocío los bueyes tiran de los carros y los caballos portan a los cofrades. Por otra parte, no hay égloga sin ovejas y el caballo Rocinante acompaña, como siempre, al más famoso caballero manchego.

Algunos compositores manifiestan actitudes patrióticas o subrayan comportamientos heroicos. Así, Emilio Serrano dedica una elegía a Fernando Villamil, el ilustre marino de Castropol que murió en la guerra de Cuba, con el fin de "enaltecer la memoria de un amigo entrañable". El compositor se refiere a él como "símbolo de una raza de mártires que no esperaban recompensa; mártires que fueron al sacrificio a sabiendas de morir sin medios de defensa y en peores condiciones de lucha que en Trafalgar noventa y tres años antes". La escena imaginada por el compositor es una especie de homenaje ante la tumba, acariciada por "el aire de la tierra que le soñó héroe y le recoge mártir". El eco de algunos cantos bélicos se combina con las tonadas de su país, que le "arrullan cariñosamente". Serrano imagina un homenaje solitario, porque "el pueblo, desconocedor de lo que simboliza esa tumba, pasará indiferente, reirá, cantará, bailará en derredor de este lugar sagrado, pero siempre habrá alguien, se oirá una voz — la de un niño tal vez-, que en su canto refleje el dolor imborrable, el agradecimiento de la patria"68.

Otros comentarios aluden al heroísmo sin dar nombres. Así, Moreno Torroba explica lo siguiente sobre el primero de sus Cuadros castellanos:

Contemplación, el primer tiempo, consta de dos motivos, que conducen a una variación del primero, en el que nos presenta la rudeza característica, plena de austeridad y espíritu guerrero de la vieja raza, luchadora siempre por altos ideales, grandes hasta la quimera, como los ilimitados horizontes de su pensamiento. ${ }^{69}$

Aunque el tono suele ser solemne, algunos personajes históricos son presentados de forma cómica, como es el caso de José Bonaparte en el Preludio de Pepe Botellas, la zarzuela que Ramos Carrión y Vives habían estrenado en 1908: "Los autores [...] pretendieron dibujar cómicamente en su obra la figura del rey José Bonaparte, conocido entre el pueblo español con dicho satírico remoquete" 170 .

Covadonga, en cambio, es una seria advocación "saturada de fe enérgica y sencilla, de fervor entusiasta, de piedad y heroísmo, con la fuerza de aquella raza bravía". Véase su programa, que combina la cultura popular con la historia y la fe:

El plan [...] se resume en los expresados sentimientos, en la batalla sobriamente descrita en su momento histórico, $y$, al alejarse esta emoción del recuerdo, queda ante el espiritu de Covadonga actual la visión escueta del paisaje y la profunda religiosidad que inspira. Un motivo de danza -la Romería-, va a unirse con otro de glorificación, terminando con el motivo inicial del poema -la Fe-, entre el solemne sonar de las campanas de la Catedral de Covadonga. ${ }^{71}$

Junto a las actitudes patrióticas señaladas en conexión con acontecimientos históricos ya mencionados (la invasión francesa, la batalla de Trafalgar, la guerra de Cuba), los compositores evocan a menudo símbolos y lugares de memoria $^{72}$ ligados por lo general a la Edad Media (Amaya o los vascos en el siglo VIII, la Reconquista, El Cid o la Alhambra) $)^{73}$.

Entre los precedentes de la "raza" española, o como oponentes a ella, salen a escena los astures y visigodos, los árabes o los israelitas españoles, un choque que en más de una ocasión, aunque no siempre, se dibuja en términos bélicos y de conflicto religioso.

El arabismo, y más específicamente el alhambrismo, servirán como espacios para la sensualidad, especialmente en su fusión con lo andaluz. Uno de los temas más exóticos lo encontramos en Kasida, el poema sinfónico de Conrado del Campo basado en un texto de Tomás Borrás, que tiene como protagonista a un viejo mendigo-músico moribundo y transcurre entre la kaisería de Xauen, la kasba de Granada y los jardines de la Alhambra ${ }^{74}$. 


\section{La recepción}

La realización de ciclos regulares de conciertos orquestales, a precios modestos, con la voluntad de abrir en ellos un hueco para los autores nacionales serían motivos suficientes para apreciar las iniciativas del Círculo de Bellas Artes. Sin embargo, aún hay un aspecto importante en este singular proyecto que es necesario considerar: la forma en que en aquellas "fiestas de arte" se produjo una especial comunicación con el público.

Sabemos que para los conciertos populares el circo "se engalanaba con tapices y plantas" 75 o se vestía con "goyescos tapices, clásicas pinturas y correctas colgaduras" ${ }^{76}$. Podríamos considerar que de ese modo el Círculo de Bellas Artes acondicionaba el espacio con su patrimonio y su buen gusto ${ }^{77}$. Sin embargo, lo cierto es que además del efecto visual había razones de peso para la ornamentación. La sala del circo era más apropiada para ver correr a los caballos que para escuchar las minuciosas interpretaciones de Pérez Casas al frente de la Filarmónica. Por ello, según el testimonio de Borrell Vidal, la comisión organizadora intentaba mejorar la acústica del local a base de "una decoración bien cerrada, un avance del escenario, la colocación de un techo supletorio y de algunos tapices para amortiguar resonancias" $" 78$.

La disposición de estos elementos y la gran afluencia de público producían un calor sofocante, al que la prensa alude en repetidas ocasiones. La sensación se agravaba además por la pesadez de la atmósfera a consecuencia de la aglomeración de fumadores en los estrechos pasillos ${ }^{79}$. " ¿No hay modo de ventilar — se escribe en El Imparcial-, de airear el teatro para que las cuerdas de los violines no estallen y el público no se ahogue?" ${ }^{80}$.

Gracias a los precios asequibles acudía a los conciertos populares una audiencia de variada composición en la que, junto a la infanta Isabel, mencionada periódicamente - alguna vez también la reina Victoria-, asistían gentes distinguidas, clases medias y populares, tal y como detalla uno de los diarios consultados:

Entramos en el teatro de Price. La amplia sala estaba llena. En palcos y butacas, lo más distinguido de Madrid; y en las entradas generales, ese público de los conciertos, en el que se funden los estudiantes, los aficionados rabiosos, la gente del pueblo. Cada día es mayor el número de los concurrentes, y esto es muy agradable, ya que habla muy alto de la pasión que en Madrid se siente por la música. ${ }^{81}$

Está claro que en el Price se daban cita personas de diferentes formaciones y hábitos culturales, pero lo que se iba a convertir en seña de identidad de aquellos encuentros es precisamente la fusión de las personas "de todas las clases sociales" 82 en una muchedumbre ardiente y entusiasta, en parte gracias a la forma y la amplitud del teatro-circo, insustituible para los fines que se perseguían

por su gran aforo de localidades baratas, sus pocos palcos y el fácil contagio de la emoción estética, que por no existir pisos independientes se transmitía de persona a persona desde las primeras filas de butacas hasta los últimos asientos de la gradería, dando ocasión a aquellas ovaciones frenéticas, inacabables, que suscitaban las ejecuciones de las obras predilectas del público. ${ }^{83}$

El concierto sinfónico se convirtió así en un fenómeno de masas. La prensa informa puntualmente de los llenos rebosantes y de que a menudo una parte del público no puede acceder al local por falta de entradas: "varios millares de personas arracimadas en todas las localidades, sin dejar el más leve huequecito"; "muchos filarmónicos tuvieron que oír el concierto desde las escalerillas de acceso a los palcos"; "en grandes grupos se retiraba contrariado de las taquillas, donde no quedaba ni un solo billete por vender"; se colgó "el cartel de 'no hay billetes'"...84.

Una concurrencia tan numerosa en los conciertos sinfónicos resultaba asombrosa y el fenómeno traía al recuerdo las actuaciones de la vieja Sociedad de Conciertos en otro teatro-circo, el del paseo de Recoletos: "Desde los tiempos, ya lejanos, de los conciertos del Príncipe Alfonso, no habían vuelto a verse favorecidas es- 
tas fiestas cultísimas por auditorios tan nutridos y fervorosos" 85 .

¿Cómo se comportaba ese público abigarrado en el espacio circular del Price? Habitualmente las sesiones estaban envueltas en un ambiente de simpatía general, que se traducía en frecuentes ovaciones. A menudo la prensa califica esas manifestaciones de "estruendosas" y "ensordecedoras", o habla de "atronadoras salvas de aplausos". Una y otra vez el auditorio se "electriza", y prácticamente siempre sale del espectáculo "haciendo unánimes y calurosas ponderaciones" de lo que ha oído, "satisfechísimo" o "archisatisfecho". Se aplaude mucho y con "entusiasmo fervoroso", pero también se insiste en que las interpretaciones se siguen con recogimiento, motivo por el que esa masa de oyentes es elogiada por los periodistas. No obstante, a veces la emoción se desborda y los murmullos o las exclamaciones interrumpen antes de tiempo la labor de los músicos ${ }^{86}$.

Ese público popular, que aplaudía, murmuraba y exclamaba, también empleaba algunas otras formas de expresión. En 1915 una voz gritó Da capo desde la galería para conseguir que una página se repitiese ${ }^{87}$ y en uno de los conciertos extraordinarios a beneficio de la Orquesta Filarmónica las manifestaciones de cariño y apoyo a la entidad y a su director se producen tal y como se describe en esta nota:

La de ayer tarde valió una serie de ovaciones delirantes a Pérez Casas y a sus músicos. El público aplaudió en masa, dando bravos, poniéndose en pie y agitando al aire los pañuelos, como entusiasta manifestación de simpatía a la nueva Orquesta, en aquella función de beneficio y de homenaje..$^{88}$

Obviamente, se trataba de un público mucho más espontáneo y efusivo que el actual y da la impresión de que su veredicto contaba en la negociación diaria con las instituciones culturales. En el tema que nos ocupa, esto afecta a la programación de obras cuando se incluían "a petición popular" y en el signo más inmediato del éxito, que consistía entonces en lograr los "honores de la repetición". Pese a la longitud de los conciertos, que constaban de tres partes —aproximadamente unas dos horas y media de duración, con dos descansos de entre quince y veinte minutos ${ }^{89}$ - cuando una obra era recibida con una de aquellas ovaciones arrolladoras la orquesta volvía a interpretarla de nuevo, bien entera o por fragmentos, lo que era posible porque aún se acostumbraba a aplaudir después de cada tiempo.

A través de esos mecanismos de aceptación - programar a petición, bisar una pieza o volver a programarla de nuevo en sucesivos conciertos- es posible medir el nivel de comprensión de la audiencia respecto al repertorio y, lo que es más importante para nuestro estudio, observar la manera en que el público contribuyó a consolidar la escuela sinfónica española.

A falta de un estudio pormenorizado sobre la recepción de cada pieza, observaremos al menos el éxito en sus aspectos más externos, señalando las obras españolas que merecieron los honores de la repetición en su primera presentación y las que, tras una buena acogida, fueron programadas de nuevo un tiempo después. Ambos aspectos quedan reflejados en el cuadro que cierra el presente trabajo.

Veintiuna de las sesenta y seis obras que hemos considerado merecieron ser bisadas en su primera interpretación: doce se repitieron completas y de las nueve restantes la orquesta interpretó de nuevo uno o dos números. A veces la solicitud del bis por parte del público era clara (en Las hilanderas se produjo "por voto unánime $\left.{ }^{\prime 90}\right)$, pero en ciertos casos había discrepancias (Catalonia se repitió "tras enconadas y divergentes manifestaciones" ${ }^{\prime 91}$ ). En realidad había éxitos francos y clamorosos, recepciones tibias (los "corteses y moderados aplausos" que obtuvo Salamanca ${ }^{92}$ ), peligrosas vacilaciones (ante la obra de Pahissa93) y fracasos estrepitosos (como el de la Fantasía gitana de Abelardo Bretón $\left.{ }^{94}\right)$.

Esta costumbre de repetir las obras que gustaban marcaba la distancia entre los actos "populares" y los de las sociedades "distinguidas". Rogelio Villar escribirá contra la costumbre de la repetición: "el buen sentido de la mayor parte del público va imponiéndose al de una minoría que quiere oír dos veces una obra en la misma sesión, en perjuicio de los intérpretes y de la 
obra". De paso el compositor y crítico que unos años más tarde escribiría un opúsculo sobre $E l$ sentimiento nacional en la música española ${ }^{95}$, abogaba por la necesidad de educar al público y señalaba que "la música no debe oírse bramando como en las plazas de toros, sino con serenidad, con devoción" ${ }^{\prime \prime 6}$. En esta cuestión, por ejemplo, la Sociedad Nacional de Música, cuyos actos se celebraban en un espacio tan elegante como el hotel Ritz, dejará bien claro en su reglamento de 1917 que en sus conciertos está terminantemente prohibido "pedir la repetición de los trozos de las obras" así como "hacer manifestaciones de desagrado a los artistas" $"$.

Por lo que respecta al segundo criterio para medir el éxito, 48 obras se escucharon una sola vez, y, en cambio, otras 18 pasaron la barrera de la primera audición al ser incluidas de nuevo en los siguientes conciertos del teatro Price. Diez de estas obras habían sido muy bien recibidas en su estreno y ya se habían repetido entonces, total o parcialmente.

Con diferencia, la obra que aparece en mayor número de programas durante estos años es el Intermedio de Goyescas de Granados - un total de nueve veces contando su estreno-, seguida por La procesión del Rocío de Turina y la Suite en La de Julio Gómez, ambas con cinco interpretaciones.

¡A mi tierra! de Pérez Casas, Elegía y añoranzas de Bretón, el Intermedio de La llama de Usandizaga y el Preludio de La Revoltosa de Chapí fueron programadas cuatro veces. Las Noches en los jardines de España de Falla sonaron en tres ocasiones.

Las diez obras restantes se repitieron una sola vez. Se trata de Las hilanderas de Villar, Los galeotes de Bretón, Tres danzas españolas de Granados, Sierra de Gredos de F. de la Viña, Égloga de Villar, Entre montañas de Valdovinos, Cuadros castellanos de Moreno Torroba, Rapsodias de la Mancha de Vega y Atardecer andaluz de Paredes.

No es fácil descubrir las razones por las que unas obras triunfaron y otras no, pero es posible apuntar algunas ideas al respecto. Las tres obras más repetidas comparten su enraizamiento en la tradición musical española, bien derivada de la música teatral (que está en el origen del frag- mento de Granados y también de la obra orquestal de Julio Gómez, elaborada a partir de los borradores de una zarzuela inédita), bien por su carácter descriptivo y cargado de referencias populares. El preludio de Goyescas se definirá como una "página sencilla y delicada", con "sabor netamente popular", que pareció al público el "eco de un corazón que hablaba sin adulaciones ni amaneramientos"98. El fragmento se caracteriza por la amplitud de sus giros melódicos y por una orquestación transparente.

En cuanto a la segunda, cuando Pérez Casas tomó la decisión de programar La procesión del Rocío, estaba seguro de que el poema sería aplaudido —así había sido siempre desde su estreno en 1912 - y con esa finalidad lo hizo sonar en febrero de 1917, retrasando prudentemente una semana el estreno de la Suite en La después del fracaso de la Fantasía gitana de Bretón hijo.

En ninguna de estas obras había intención de imitar la grandilocuencia de Richard Strauss ni tampoco la finura de Claude Debussy, los dos modelos que en los tiempos de la Gran Guerra dividían a los compositores españoles y que, en pleno conflicto, tenían una carga no solo estética sino también política. En ese aspecto la obra de Turina es muy clara al referirse a una conocida fiesta religiosa e incluir la cita directa de la Marcha Real. Aun sin conocer la alineación política del autor, que acabaría trabajando en la Comisaría de la Música durante el franquismo, los signos hablan por sí mismos.

Mientras tanto la Suite en La, por la que su autor sería encasillado en el "nacionalismo popular", es una de las pocas piezas de nuestro repertorio que no se ajusta a un perímetro regional. El compositor, en este caso un liberal de izquierdas, manifiesta en las notas que se trata de una obra "sin asunto literario" y con "sabor marcadamente nacional", pero no apunta referencias tradicionales citadas con literalidad. Solo en cuanto al tiempo titulado "Canción popular" hace una vaga alusión a los antiguos israelitas españoles, que ya ha sido mencionada. El éxito de esta suite fue uno de los más destacados y supuso la consagración del compositor, que entonces tenía apenas treinta años. Los movimientos tercero y cuarto 
fueron repetidos y dos semanas más tarde la obra se programó de nuevo "a petición popular". Dejando al margen otras valoraciones discordantes, la crítica coincidió en señalar que el carácter nacional de la obra, la sinceridad del autor y la sencillez de la factura explicaban la aceptación por parte de un público de comportamiento más emocional que intelectual, y para entonces ya algo cansado de las exhibiciones técnicas y las pretensiones retóricas de otros autores ${ }^{99}$.

El conjunto de obras repetidas en el Price durante los años de la guerra europea y los inicios de la dictadura de Primo de Rivera muestra que la mayor parte de este repertorio fue creado entre 1912 y 1923, por lo que el intento colectivo de definir un estilo sinfónico español pertenecía al "presente" del momento, sin perjuicio de que alguna nueva música utilizara un estilo de tiempos pretéritos, algo lógico teniendo en cuenta la edad de compositores como Giménez o Bretón. Por lo demás, hay que decir que se mantiene la vigencia de algunas piezas de etapas anteriores como el Preludio de $L a$ Revoltosa o la suite iA mi tierra! —escritas ambas en 1897-, y de alguna otra compuesta en la primera década del siglo XX como es el caso de Los galeotes.

Se ha afirmado que los sentimientos y las aspiraciones soterradas de los nacionalismos se relacionan principalmente con tres referentes: el territorio, la historia y la comunidad ${ }^{100}$. El imaginario español que se presenta a través del sonido sinfónico es precisamente el de los paisajes naturales y las escenas campesinas, las fiestas y las romerías, ensambladas a menudo con el recuerdo de algún episodio o personaje histórico (a veces literario o pictórico). Ese naturalismo, costumbrismo o realismo, según los casos, afecta a la nación-pueblo (y no a la nación-Estado) ante la cual el compositor se convierte en profeta y modelo. El público ve cómo el artista añora la patria y cuáles son sus emociones ante el paisaje o las celebraciones colectivas, lo comprende y se conmueve. De ese modo el entusiasmo prende entre la multitud.
La respuesta de aquella audiencia miscelánea en los conciertos del Price funcionó como un barómetro mesocrático de los gustos musicales en los años diez y veinte, una etapa en la que la Generación de los Maestros efectúa la transición entre las tradiciones teatrales heredadas del siglo XIX y la renovación que pronto buscaría la Generación del 27. Aquellas "fiestas de arte" vinieron a ocupar un espacio intermedio entre manifestaciones elitistas y minoritarias - las funciones operísticas del Teatro Real, las sesiones de la Sociedad Filarmónica o las de la Sociedad Nacional de Música- y otros espacios culturales menos selectos-la música de banda, los coros de aficionados, la zarzuela, el teatro por horas o el género chico y las variedades - ${ }^{101}$. Su seña de identidad en este contexto es precisamente haber tratado de tender puentes difundiendo, como se ha repetido varias veces, un arte elevado entre la gran masa española.

La musicología suele identificar el llamado "nacionalismo de la esencias" o "nacionalismo universalista" con una línea que parte de las formulaciones teóricas de Pedrell, pasa por las obras de Albéniz y Granados, y culmina en las obras de Manuel de Falla, las más reconocidas fuera del país y las más ensalzadas por un sector de la crítica. En este otro nacionalismo, que podría llevar el apellido de "popular", el aliado no es la crítica sino el público y su fuerza no va a ser estética sino social y sentimental.

Por eso es importante observar la eficacia de la estrategia empleada por el Círculo, cuando en 1915 plantea la necesidad de sellar un compromiso entre la entidad, el público y los compositores, a fin de desarrollar entre todos - creando comunidad- una escuela sinfónica española que se presenta como empresa patriótica.

Autores de la vieja escuela como Bretón y Serrano, los impulsores de la idea, trabajaron intensamente por la divulgación de la música sinfónica desde una postura regeneracionista. Pérez Casas, cuya incansable labor todavía no ha sido suficientemente reconocida, defendió siempre lo que en la época se llamaba popularismo. En su discurso de ingreso en la Academia el autor de la suite murciana reflexionaría sobre Los conciertos como signo de la cultura musical 
de los pueblos (1925). Años más tarde formaría parte de la primera Junta Nacional de Música, un organismo creado mediante el decreto firmado por Alcalá-Zamora, también fuertemente "nacionalizado", que empezaba diciendo: "La expresión más genuina del alma de los pueblos, la que señala el ritmo de su carácter más directamente, es su música popular" ${ }^{102}$.

Finalmente, si es cierto que la nación se construye diariamente a través de las prácticas cotidianas, quizá el aspecto más significativo de las "fiestas de arte" desarrolladas en el teatro de la plaza del Rey sea la manera en que el ritual del concierto popular se definió como un lugar de negociación en el que se buscaba el consenso respecto a lo que podía o debía ser la música sinfónica española, funcionando a la vez como un espacio de ensayo para anclar la identidad nacional a través del sentimiento y la emoción, una herramienta fundamental para las "religiones políticas" y los movimientos de masas del período de entreguerras. 
ANEXO

Relación de las obras españolas interpretadas en las 14 primeras temporadas de los conciertos populares patrocinados por el Círculo de Bellas Artes de Madrid

\begin{tabular}{|c|c|c|c|c|c|}
\hline AÑo & TÍTULO DE LA OBRA & COMPOSITOR & $\begin{array}{l}\text { HONORES } \\
\text { DE LA } \\
\text { REPETICIÓN }\end{array}$ & $\begin{array}{c}\text { N. }{ }^{\circ} \text { TOTAL DE IN- } \\
\text { TERPRETACIONES } \\
\text { (HASTA LA TEMP. } \\
\text { 1923-1924) }\end{array}$ & $\begin{array}{c}\text { A } \\
\text { PETICIÓN } \\
\text { POPULAR }\end{array}$ \\
\hline \multirow[t]{6}{*}{1915} & Las hilanderas & R. Villar & $x$ & 2 & \\
\hline & Escenas andaluzas & T. Bretón & Zapateado & 2 (Polo) & $x$ \\
\hline & Primera sinfonía & F. Calés & Scherzo & 1 & \\
\hline & Los galeotes & T. Bretón & & 2 & \\
\hline & $\begin{array}{l}\text { Elegía a la memoria de } \\
\text { Fernando Villamil }\end{array}$ & E. Serrano & & 1 & \\
\hline & ¡A mi tierra! (tres mov.) & B. Pérez Casas & & $\begin{array}{l}4 \text { (primer } \\
\text { movimiento) }\end{array}$ & $\mathrm{x}$ \\
\hline \multirow[t]{9}{*}{1916} & Escenas populares & R. Villar & & 1 & \\
\hline & Intermedio de Goyescas & E. Granados & $\mathrm{x}$ & 9 & $x$ \\
\hline & Tres danzas españolas & $\begin{array}{l}\text { E. Granados (instr. } \\
\text { Lamote de Grignon) }\end{array}$ & $\begin{array}{l}\text { Andaluza } \\
\text { Rondalla }\end{array}$ & $\begin{array}{l}2 \text { (solo dos } \\
\text { danzas) }\end{array}$ & \\
\hline & $\begin{array}{l}\text { Una aventura de don } \\
\text { Quijote }\end{array}$ & J. Guridi & $\mathrm{x}$ & 1 & \\
\hline & Catalonia & I. Albéniz & $\mathrm{x}$ & 1 & \\
\hline & Salamanca & T. Bretón & & 1 & \\
\hline & $\begin{array}{l}\text { Los gnomos de la } \\
\text { Alhambra }\end{array}$ & R. Chapí & & 1 & \\
\hline & Sierra de Gredos & F. de la Viña & & 2 & \\
\hline & Jimena y Rodrigo & M. Manrique de Lara & & 1 & \\
\hline \multirow[t]{7}{*}{1917} & Fantasía gitana & A. Bretón & & 1 & \\
\hline & La procesión del Rocío & J. Turina & $\mathrm{x}$ & 5 & $\mathrm{x}$ \\
\hline & Suite en La & J. Gómez & $\begin{array}{l}\text { Canción } \\
\text { popular } \\
\text { Danza }\end{array}$ & 5 & $x$ \\
\hline & ¡Alma española! & M. ${ }^{a}$ Rodrigo & & 1 & \\
\hline & Tres preludios vascos & $\begin{array}{l}\text { P. J. A. de San } \\
\text { Sebastián }\end{array}$ & $\begin{array}{l}\text { La } \\
\text { hilandera }\end{array}$ & 1 & \\
\hline & Elegía y añoranzas & T. Bretón & & 4 & \\
\hline & Valencianas & E. López Chavarri & & 1 & \\
\hline
\end{tabular}




\begin{tabular}{|c|c|c|c|c|c|}
\hline \multirow[t]{2}{*}{ AÑo } & TÍTULO DE LA OBRA & COMPOSITOR & \multirow[t]{2}{*}{$\begin{array}{l}\text { HONORES } \\
\text { DE LA } \\
\text { REPETICIÓN }\end{array}$} & $\begin{array}{c}\mathrm{N} .^{\circ} \text { TOTAL DE IN- } \\
\text { TERPRETACIONES } \\
\text { (HASTA LA TEMP. } \\
\text { 1923-1924) }\end{array}$ & \multirow[t]{2}{*}{$\begin{array}{c}\text { A } \\
\text { PETICIÓN } \\
\text { POPULAR }\end{array}$} \\
\hline & $\begin{array}{l}\text { Obertura sobre un tema } \\
\text { popular catalán }\end{array}$ & J. Pahissa & & 1 & \\
\hline \multirow[t]{4}{*}{1918} & Añoranzas & P. Blanco & $\begin{array}{c}\text { dos } \\
\text { números }\end{array}$ & 1 & \\
\hline & $\begin{array}{l}\text { Noches en los jardines de } \\
\text { España }\end{array}$ & M. de Falla & & 3 & $\mathrm{x}$ \\
\hline & $\begin{array}{l}\text { La leyenda de Santa } \\
\text { Casilda }\end{array}$ & $\begin{array}{l}\text { M. López Roberts } \\
\text { (instr. T. Valdovinos) }\end{array}$ & & 1 & \\
\hline & Égloga & R. Villar & & 2 & \\
\hline \multirow[t]{5}{*}{1919} & Añoranzas & L. Aula & & 1 & \\
\hline & $\begin{array}{l}\text { Granada, un atardecer en } \\
\text { la Alhambra }\end{array}$ & A. Gaos & & 1 & \\
\hline & Intermedio de La llama & R. Usandizaga & $x$ & 4 & $x$ \\
\hline & Cuatro preludios vascos & $\begin{array}{l}\text { P. J. A. de San } \\
\text { Sebastián }\end{array}$ & & 1 & \\
\hline & Cuadros & F. Moreno Torroba & & 1 & \\
\hline \multirow[t]{5}{*}{1920} & Córdoba & $\begin{array}{l}\text { I. Albéniz } \\
\text { (instr. A. Larrocha) }\end{array}$ & & 1 & \\
\hline & Danzas fantásticas & J. Turina & Ensueño & 1 & \\
\hline & Por tierras de Castilla & F. de la Viña & & 1 & \\
\hline & Égloga & J. Blanco-Recio & & 1 & \\
\hline & Preludio de La Revoltosa & R. Chapí & $x$ & 4 & $x$ \\
\hline \multirow[t]{9}{*}{1921} & $\begin{array}{l}\text { Intermedio de La boda de } \\
\text { Luis Alonso }\end{array}$ & G. Giménez & & 1 & $x$ \\
\hline & Campesina & P. Sanjuán & & 1 & \\
\hline & Arrabales castellanos & J. Aroca & & 1 & \\
\hline & Preludio de Garín & T. Bretón & & 1 & $x$ \\
\hline & Fantasía morisca & R. Chapí & Serenata & 1 & $x$ \\
\hline & $\begin{array}{l}\text { La primera salida de don } \\
\text { Quijote }\end{array}$ & E. Serrano & & 1 & $\mathrm{x}$ \\
\hline & Preludio de Pepe Botellas & A. Vives & $x$ & 1 & $x$ \\
\hline & Entre montañas & T. Valdovinos & $x$ & 2 & \\
\hline & La torre del Oro & G. Giménez & & 1 & \\
\hline
\end{tabular}




\begin{tabular}{|c|c|c|c|c|c|}
\hline AÑo & TíTULO DE LA OBRA & COMPOSITOR & $\begin{array}{l}\text { HONORES } \\
\text { DE LA } \\
\text { REPETICIÓN }\end{array}$ & $\begin{array}{c}\text { N. }{ }^{\circ} \text { TOTAL DE IN- } \text { - } \\
\text { TERPRETACIONES } \\
\text { (HASTA LA TEMP. } \\
\text { 1923-1924) }\end{array}$ & $\begin{array}{c}\text { A } \\
\text { PETICIÓN } \\
\text { POPULAR }\end{array}$ \\
\hline & Bolero & T. Bretón & & 1 & \\
\hline & Panaderos & T. Bretón & & 1 & \\
\hline & Cuadros castellanos & F. Moreno Torroba & & 2 & \\
\hline & Tríptico gallego & B. García de la Parra & $x$ & 1 & \\
\hline & Dolora sinfónica & G. Baudot & & 1 & \\
\hline & Rapsodias de la Mancha & L. Vega & & 2 & \\
\hline \multirow[t]{5}{*}{1922} & El sombrero de tres picos & M. de Falla & una danza & 1 & \\
\hline & Tarantela & J. Larregla & $x$ & 1 & \\
\hline & El poble está en festa & F. Balaguer & & 1 & \\
\hline & Kasida & C. del Campo & & 1 & \\
\hline & Boceto andaluz & P. García Morales & & 1 & \\
\hline \multirow[t]{8}{*}{1923} & Jota de La Dolores & T. Bretón & & 1 & \\
\hline & Canciones & J. Gómez & & 1 & \\
\hline & Suite de Amaya & J. Guridi & $\begin{array}{l}\text { Espata- } \\
\text { dantza }\end{array}$ & 1 & \\
\hline & $\begin{array}{l}\text { Melodía religiosa sobre } \\
\text { un tema popular vasco }\end{array}$ & V. Arregui & & 1 & \\
\hline & Atardecer andaluz & A. Paredes & $x$ & 2 & \\
\hline & $\begin{array}{l}\text { Preludio de La verbena de } \\
\text { la Paloma }\end{array}$ & T. Bretón & & 1 & \\
\hline & $\begin{array}{l}\text { Impresiones de Granada - } \\
\text { Zambra en el Albaicín }\end{array}$ & A. Barrios & & 1 & \\
\hline & Sinfonía sevillana & J. Turina & & 1 & \\
\hline 1924 & Covadonga & F. de la Viña & & 1 & \\
\hline
\end{tabular}




\section{NOTAS}

${ }^{1}$ Entre otros estudios de conjunto sobre el nacionalismo musical español en el primer tercio del siglo XX, cabe destacar los que se citan a continuación, aunque sin pretensiones de exhaustividad. Casares, Emilio: "La música española hasta 1939 o la restauración musical", Actas del Congreso Internacional "España en la música de Occidente". Madrid: INAEM, 1987, vol. 2, pp. 261-322; Martínez del Fresno, Beatriz: "El pensamiento nacionalista en el ámbito madrileño (19001936). Fundamentos y paradojas". En De Musica Hispana et Aliis. Miscelánea en honor al prof. Dr. José López-Calo, S. J. E. Casares y C. Villanueva (coords.). Universidade de Santiago de Compostela, 1990, vol. II, pp. 351397; id.: "Nacionalismo e internacionalismo en la música española de la primera mitad del siglo XX", Revista de Musicología, vol. XVI, n. ${ }^{\circ} 1$ (1993), pp. 640-657; Labajo, Joaquina: "Política y usos del folklore en el siglo XX español", Revista de Musicología, vol. XVI, n. ${ }^{\circ} 4$ (1993), pp. 1988-1997; Pérez Zalduondo, Gemma: "El nacionalismo como eje de la política musical del primer gobierno regular de Franco (30 de enero de 1938-8 de agosto de 1939", Revista de Musicología, vol. XVIII (1995), pp. 247-273; Costa, Luis: "Coralismo, etnicidad y nacionalismo en Galicia", Cuadernos de Música Iberoamericana, vol. 6 (1998), pp. 49-63; id.: La formación del pensamiento musical nacionalista en Galicia hasta 1936. Tesis doctoral, CD-ROM. Universidade de Santiago de Compostela, 1999; Alonso, Celsa: "Nacionalismo". En: Diccionario de la música española e hispanoamericana. E. Casares et alii (coords.). Madrid: ICCMU, 2000, vol. 7, pp. 924-944; Nagore Ferrer, María: "La realidad musical vasca en el período de entreguerras". En: Música española entre dos guerras. J. Suárez-Pajares (ed.). Granada: Archivo Manuel de Falla, 2002, pp. 135-163; Costa, Luis: "Del folklorismo a la vanguardia. Jesús Bal o 'Simón del Desierto'". En: Jesús Bal y Gay. Tientos y silencios (1905-
1993). C. Villanueva (ed.). Madrid: Residencia de Estudiantes, 2005, pp. 223-255; Pérez Zalduondo, Gemma: "Racial discourses in Spanish Musical Literature, 1915-1939". En: Western Music and Race. J. Brown (ed.). Cambridge University Press, 2007; Lamas, Rafael: Música e identidad. El teatro musical español y los intelectuales en la Edad Moderna. Madrid: Alianza, 2008; Villanueva, Carlos: "El nacionalismo musical en la obra de Alejo Carpentier", Cuadernos de Música Iberoamericana, vol. 15 (2008), pp. 119-131; Alonso, Celsa et alii: Creación musical, cultura popular y construcción nacional en la España contemporánea. Madrid: ICCMU, 2010.

${ }^{2}$ En este sentido Taruskin critica la presentación que del tema hacía todavía Willy Apel en el Harvard Dictionary of Music editado en 1969. Taruskin, Richard: "Nationalism". En: The New Grove Dictionary of Music and Musicians, 2. ${ }^{\mathrm{a}}$ ed. New York: Grove, 2011, vol. 17, p. 689

Esta visión ha sido desmontada en trabajos realizados desde otros presupuestos, como los de Pamela Potter (Most German of the Arts: Musicology and Society from the Weimar Republic to the End of Hitler's Reich. New Haven: Yale University, 1998), Jane Fulcher (French Cultural Politics and Music: from the Dreyfus Affair to the first World War. New York: Oxford University Press, 1999) y Marco Gervasoni (Le armi di Orfeo. Musica, identità nazionali e religioni politiche nell'Europa del Novecento. Milano: La Nuova Italia, 2002), por citar solo tres libros realizados desde los países mencionados y referidos a la música (y a la musicología) del siglo XX. Otros estudios recientes están recogidos en monografías colectivas entre las que destacan Music and the Racial Imagination. R. Radano y Ph. V. Bohlman (eds.). University of Chicago Press, 2000; Musical Constructions of Nationalism. Essays of the History and Ideology of European Musical Culture, 1800-1945. H. White y M. Murphy (eds.). Cork University Press, 2001; y Western Music and Race. J. Brown (ed.). Cambridge University Press, 2007.

3 Ya Dahlhaus señalaba que lo que se percibe como nacional (o no) depende principalmente de la opinión colectiva. Dahlhaus, Carl: "Nationalism and music". En: Between Romanticism and Modernism. Four Studies in the Music of the Later Ninteenth Century. University of California Press, 1980, pp. 79-101.

${ }^{4}$ La música en los procesos de construcción nacional: discursos y prácticas fue el título de un Seminario Internacional desarrollado en la Universidad de la Rioja en mayo de 2010. Próximamente se publicará un libro colectivo coordinado por Pilar Ramos.

${ }^{5}$ Aplico la terminología propuesta en Máiz, Ramón: "Federalismo y nación en el discurso del nacionalismo gallego". En: Los nacionalismos en la España de la Il República. J. G. Beramendi y R. Máiz (eds.). Madrid: Siglo XXI, 1991, pp. 377-404.

${ }^{6}$ Programa de la primera serie de conciertos populares $(4,11$ y 18 de diciembre de 1914). En esta serie y en la siguiente (celebrada los días 22 y 29 de enero y 5 de febrero de 1915)، actuó la Orquesta Sinfónica de Madrid dirigida por el maestro Bretón. Las series sucesivas correrían, en cambio, a cargo de la Orquesta Filarmónica dirigida por Bartolomé Pérez Casas.

${ }^{7}$ Véase Martínez del Fresno, Beatriz: Julio Gómez. Una época de la música española. Madrid: ICCMU 1999, p. 108. El capítulo III de esta monografía contiene epígrafes dedicados a "Los conciertos sinfóncos en Madrid", "El Círculo de Bellas Artes y los conciertos populares", "La Orquesta Filarmónica", "Nacionalismo y extranjerismo en el nuevo repertorio sinfónico" y "Los concursos del Círculo", pp. 105-119.

8 José Luis Temes afirma que el éxito de los conciertos populares permaneció invariable hasta 1924, fecha en que fue necesario trasladarlos a teatro Apolo, "lo que comenzó a dislocar la fórmula infalible". Después hubo una nueva mudanza al teatro de 
Centro para la temporada 1925-1926, y en noviembre de 1926 se intentó celebrar los conciertos en la propia sede del Círculo, aunque pronto las autoridades prohibieron ese uso del espacio. El Círculo hizo todavía un esfuerzo para programar la temporada 1927-1928 en el teatro de la Zarzuela pero, según Temes, "las circunstancias habían cambiado: en 1914 los gastos que originaban estos conciertos eran moderados, y el Círculo era una entidad boyante; ahora, los gastos se habían disparado, y el Círculo era una entidad cargada de deudas impagables". Temes, José Luis: El Círculo de Bellas Artes. Madrid, 1880-1936. Madrid: Alianza Editorial, 2000, pp. 229-230. En un artículo posterior, el mismo autor resume las actividades de "La Sección de Música del Círculo de Bellas Artes de Madrid, 1880-1936", Cuadernos de Música Iberoamericana, vol. 8-9 (2001), pp. 243-254. En la crisis de los conciertos populares incide directamente la dictadura de Primo de Rivera, ya que la prohibición de llevar a cabo juegos de azar hizo perder a la institución una importante fuente de ingresos. Un examen de esa crisis, así como un análisis de la programación una vez que los conciertos dejan de hacerse en el teatro Price, se encuentra en Palacios, María: La renovación musical en Madrid durante la dictadura de Primo de Rivera. El Grupo de los Ocho (1923-1931). Madrid: Sociedad Española de Musicología, 2008, pp. 75-86.

9 Véase Navascués Navarro, Pedro: Arquitectura española (18081914). Madrid: Espasa Calpe, 1993. Summa Artis XXXV/2, pp. 435-436.

10 Los datos económicos que menciono han sido extraídos de los programas de mano conservados en el Archivo del Círculo de Bellas Artes y de las liquidaciones publicadas en diversos números del Boletín del Círculo de Bellas Artes comprendidos entre enero de 1915 y febrero de 1920.

11 En la monografía sobre la Orquesta Sinfónica se afirma que "en ese momento eran los conciertos mejor pagados de Madrid". Gómez Amat, Carlos y Joaquín Turina Gómez: La Orquesta Sinfónica de Madrid. Noventa años de historia. Madrid: Alianza Editorial, 1994, p. 66. El 20 de enero de 1917 la Junta directiva del Círculo de Bellas Artes aprobaría el aumento de 500 pesetas por concierto solicitado por la Orquesta Filarmónica.

${ }^{12}$ En las fuentes de los años 1915 a 1920 constan déficits de 752, 838 y 5.991 pesetas (prescindo de los decimales) en alternancia con superávits de 13, 4.594, 2.301 y 260 pesetas. Caso distinto es el de los conciertos benéficos, cuyas localidades eran más caras y que, por definición, debían obtener superávit para cumplir su función. Por ejemplo, se obtuvieron 2.587 pesetas en el concierto a beneficio de los heridos en la campaña de África en 1915 y 1.960 en el celebrado a beneficio de la Caja de la Sección benéfica del Círculo en 1919.

13 Boletín del Círculo de Bellas Artes, n. ${ }^{\circ} 48$, febrero de 1917, p. 7.

${ }^{14}$ Citado por Gómez Amat, Carlos: "Bartolomé Pérez Casas y la Orquesta Filarmónica de Madrid", Cuadernos de Música, año I, n. ${ }^{\circ} 4$ (1983), p. 47.

15 "Advertencia importante". Programa del 36. ${ }^{\circ}$ concierto popular, 9$\mathrm{XI}$-1917. Sobre la influencia del director y la agrupación en la introducción de música nueva en Madrid, véase Gómez Amat, Carlos: "Bartolomé Pérez Casas y la Orquesta Filarmónica de Madrid", Cuadernos de Música, año I, n. ${ }^{\circ} 4$ (1983), pp. 39-52. Ángel Sagardía había hecho previamente una somera aproximación al repertorio de la Filarmónica en "Orquestas Sinfónica, Filarmónica de Madrid y Nacional", Música, Revista trimestral de los Conservatorios españoles, n. ${ }^{\circ}$ 8-9 (1954), pp. 35-79, dedicándole en particular las pp. 49-65. Más reciente y más amplio es el trabajo de Cuadrado Caparrós, María Dolores: Bartolomé Pérez Casas y la Orquesta Filarmónica de Madrid (1915-1936). Valencia: Germania,
2007. Esta autora no se fija específicamente en los conciertos populares del circo Price sino en todos los desarrollados por la orquesta a lo largo de 22 temporadas. A partir de la consulta de 833 programas de mano, con 220 autores, 660 obras y 4.832 interpretaciones, ofrece en su libro un análisis principalmente estadístico de la actividad de la orquesta.

${ }^{16}$ En el archivo del Círculo de Bellas Artes se conserva muy fragmentariamente la información relativa a las actividades de la Sección de Música, debido probablemente a la pérdida de documentos durante la Guerra Civil española.

17 Programa del $4 .^{\circ}$ concierto popular, 22-I-1915. Las obras premiadas en el concurso de obras sinfónicas convocado por el Círculo en 1912 cuyo estreno se produjo en los primeros conciertos populares son: Las hilanderas de Rogelio Villar y Baile de muñecas de Abelardo Bretón (22-I1915), Hero y Leandro de Facundo de la Viña (29-I-1915) y Primera sinfonía de Francisco Calés y Pina (12-II-1915). En 1915 el Círculo organizó un segundo concurso de obras sinfónicas en el que resultaría premiado el poema sinfónico Una aventura de don Quijote de Jesús Guridi.

${ }^{18}$ Presentación de la ll temporada (1915-1916). Programa del 8. ${ }^{\circ}$ concierto popular, 12-XI-1915. Las trece primeras sesiones fueron numeradas por series. A partir del $14 .^{\circ}$ los conciertos populares seguirán una numeración correlativa. Por cuestiones de claridad he decidido aplicar este sistema también a las primeras series, identificando los conciertos por el número que tendrían dentro de la totalidad.

${ }^{19}$ Presentación de la III temporada (1916-1917).

${ }^{20}$ Presentación de la IV temporada (1917-1918).

${ }^{21}$ Presentación de la $\mathrm{V}$ temporada (1918-1919).

22 Programa del 89. concierto popular, 14-I-1921 (la portada señala por error el año 1920). 
23 "Al público". Programa del 95. concierto popular, 11-III-1921. El texto continúa pidiendo disculpas a otros 37 compositores "tan prestigiosos como Albéniz, Arregui, Gerónimo Giménez, Pérez Casas, Guridi, Oscar Esplá, Pedrell, Facundo de la Viña, Conrado del Campo, Lloret, Esbrí, García Morales, Baudot, Villa, Pahissa, Lamote de Grignon, Moreno Torroba, Sanjuán, Calés, Luna, Morera, Padre San Sebastián, Salazar, Nogués, Rogelio del Villar, Bretón (A.), Isasi, Vila, Larregla, López Chavarri, Manén, Arenas, Blanco, Aula, Mariani, María Rodrigo, Gaos y otros muchos que sería prolijo enumerar; maestros a los que el Círculo de Bellas Artes, con la Orquesta Filarmónica y la Comisión organizadora de sus conciertos, se complacen en rendir desde aquí, al lamentar que por las antedichas razones no se interpreten obras suyas en la tarde de hoy, los más cordiales testimonios de admiración".

${ }^{24}$ Programa del $100 .^{\circ}$ concierto popular, 11-IX-1921.

${ }^{25}$ El concierto popular n. ${ }^{\circ} 144$, celebrado el 29-II-1924, es el último que tiene lugar en el teatro Price.

${ }^{26}$ No he incluido en este número alguna obra que interpretaban al piano los solistas invitados.

${ }^{27}$ Las 19 obras que no tendré en cuenta en este artículo son las siguientes: Baile de muñecas (A. Bretón), Hero y Leandro (F. de la Viña), Historia de una madre (V. Arregui), Amor dormido (A. Isasi), Afrodita (P. Sanjuán), Poema romántico (J. Lamote de Grignon), Poema de niños (O. Esplá), El año mil (A. Vila), "Oración y escena de los ángeles" del oratorio San Francisco (V. Arregui), Variaciones sobre un tema de Tartini (J. Manén), Hasshan y Melihah-Fantasía Danza (R. Usandizaga), Balada (J. Gómez), Lento y triste, a modo de una marcha fúnebre (V. Arregui), Pantomima-suite (M. López Roberts), Año nuevo (L. Mariani), El sueño de Eros (O. Esplá), Concierto para violonchelo y orquesta (E. Morera), Dos bocetos para orquesta (E. Halffter) y Evangelio de Navidad (J. Turina).
${ }^{28}$ Casi todos los compositores que mencionaré se formaron en la segunda mitad del siglo XIX. La década de 1850, que dio grandes talentos para el teatro musical, vio nacer a Bretón, Serrano y Giménez, que en los años de los conciertos del Price se encuentran en la sesentena y están aún en activo. Bretón y Giménez morirán en 1923. Ruperto Chapí había fallecido en 1909.

Entre los nacidos en la década siguiente, la de 1860 , se ubican Albéniz y Granados, dos figuras muy destacadas de la primera oleada del nacionalismo musical español. Albéniz había fallecido en 1909 y Granados morirá en 1916 al regresar del estreno de Goyescas en Nueva York. De este pequeño grupo, solo Joaquín Larregla y el wagneriano Manuel Manrique de Lara siguen activos en los años que nos ocupan.

Catorce de los compositores programados nacieron a partir de 1870 . Junto a Enrique Morera, Eduardo López Chavarri, Amadeo Vives, Mauricio López Roberts, Bartolomé Pérez Casas (el director de la Orquesta Filarmónica), Andrés Gaos, Rogelio Villar, Luis Aula, Jesús Aroca, Facundo de la Viña, Luis Vega Manzano, Conrado del Campo y Pedro García Morales, se destaca Manuel de Falla, cabeza visible de la que se puede considerar equivalente a la Generación del 98 en la música.

Otros quince autores han venido al mundo en la década de 1880: Jaime Pahissa, Joaquín Turina, Ángel Barrios, Teodoro Valdovinos, Pedro Blanco, Benito García de la Parra, Gregorio Baudot, Antonio Paredes, Julio Gómez, Jesús Guridi, José Antonio de San Sebastián, Ramón Usandizaga, José Ramón Blanco-Recio, Abelardo Bretón (hijo de Tomás Bretón) y la única mujer compositora que aparece en los programas, María Rodrigo, forman parte de la llamada Generación de los Maestros.

Los más jóvenes de entre los creadores que consideraré son Federico Moreno Torroba y Francisco Balaguer, ya que han nacido en el último decenio del siglo XIX.

${ }^{29}$ Programas del $41 .^{\circ}$ concierto popular (14-XII-1917) y del 109. ( 3-II1922), respectivamente.

${ }^{30}$ María Rodrigo: ¡Alma española!, impresiones sinfónicas (34. ${ }^{\circ}$ concierto popular [en adelante, "concierto popular" se abreviará

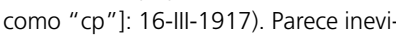
table entender que en esta obra hay un reflejo de la propia María Rodrigo. Según las notas al programa, en lucha contra las circunstancias adversas, "el artista" pasa por cuatro estados emocionales que se corresponden con cada una de las partes de la pieza: se muestra decidido y noble, dispuesto a emigrar en el primer movimiento ("El héroe"), melancólico una vez que se encuentra fuera de su país ("Añoranzas"), alegre cuando regresa en el tercer movimiento ("Danzas") e inundado de amor y entregado sinceramente a su arte en el tiempo final ("La alegría-el amor").

${ }^{31}$ B. Pérez Casas: ¡A mi tierra! (Escenas murcianas), tres primeros tiempos (13. ${ }^{\circ} \mathrm{cp}:$ 17-XII-1915); R Villar: Escenas populares, impresiones sinfónicas (20. ${ }^{\circ}$ cp: 3-III-1916); I. Albéniz: Catalonia, suite popular $\left(23 .^{\circ} \mathrm{cp}\right.$ : 24-XI-1916); J. Pahissa: Obertura sobre un tema popular catalán (41. cp: 14-XII-1917); T. Bretón: Salamanca, poema sinfónico (24. ${ }^{\circ} \mathrm{cp}: 1-\mathrm{XII}$ 1916); E. López Chavarri: Valencianas, cuadros levantinos (40. ${ }^{\circ} \mathrm{cp}:$ 7-XII1917); F. de la Viña: Covadonga, evocación sinfónica (144. ${ }^{\circ} \mathrm{cp}$ : 29-II-1924).

${ }^{32}$ F. de la Viña: Sierra de Gredos, evocación sinfónica en forma de poema (26. $\left.{ }^{\circ} \mathrm{cp}: 15-\mathrm{XII}-1916\right)$.

33 J. R. Blanco-Recio: Égloga, boceto sinfónico (77. ${ }^{\circ} \mathrm{cp}$ : 5-III-1920).

${ }^{34}$ B. García de la Parra: Tríptico gallego (103. ${ }^{\circ} \mathrm{cp}:$ 2-XII-1921).

${ }^{35}$ P. J. A. de San Sebastián: Tres preludios vascos, para orquesta (37. ${ }^{\circ}$ cp: 16-XI-1917).

36 J. Aroca: Arrabales castellanos, bocetos (93. $\left.{ }^{\circ} \mathrm{cp}: 18-11-1921\right)$.

${ }^{37}$ R. Villar: Las hilanderas, impresión sinfónica (4. ${ }^{\circ} \mathrm{cp}$ : 22-I-1915). 
38 Los cuadros son, respectivamente, "La era" y "El baile de San Antonio de La Florida", "Nuestro Señor crucificado" y "Ninfas de Diana sorprendidas por los sátiros". Programa del 19-XII-1919.

${ }^{39}$ T. Bretón: Los galeotes, poema sinfónico (11. $\left.{ }^{\circ} \mathrm{cp}: 3-X \mathrm{II}-1915\right)$.

${ }^{40} \mathrm{~J}$. Guridi: Una aventura de don Quijote, poema sinfónico (22. ${ }^{\circ} \mathrm{cp}$ : $17-$ XI-1916).

${ }^{41}$ Sobre "Música y territorio" se ha publicado un interesante dossier bibliográfico compilado por Natalie Morel Borotra e Itziar Larrinaga Cuadra, Musiker, n. 17 (2010), pp. 389417.

${ }^{42}$ T. Bretón: Los galeotes, poema sinfónico (11. ${ }^{\circ} \mathrm{cp}$ : 3-XII-1915); F. de la Viña: Sierra de Gredos, evocación sinfónica en forma de poema $\left(26{ }^{\circ} \mathrm{cp}\right.$ : 15-XII-1916); M. Manrique de Lara: Jimena y Rodrigo, escena de amor de un drama lírico (27. ${ }^{\circ} \mathrm{cp}$ : 22-XII-1916); J. R. Blanco-Recio: Égloga, boceto sinfónico (77. ${ }^{\circ} \mathrm{cp}$ : 5-III-1920).

${ }^{43}$ F. de la Viña: Sierra de Gredos, evocación sinfónica en forma de poema (26. ${ }^{\circ}$ cp: 15-XII-1916).

44 J. R. Blanco-Recio: Égloga, boceto sinfónico (77. ${ }^{\circ} \mathrm{cp}$ : 5-III-1920).

${ }^{45}$ T. Valdovinos: Entre montañas, boceto sinfónico (96. ${ }^{\circ} \mathrm{cp}: 11-\mathrm{III}-1921$ ).

${ }^{46}$ M. López Roberts: La leyenda de Santa Casilda, poema sinfónico con instrumentación de T. Valdovinos (49. ${ }^{\circ} \mathrm{cp}: 12-$-II-1918).

${ }^{47}$ M. de Falla: Noches en los jardines de España, impresiones sinfónicas para piano y orquesta $\left(46 .^{\circ} \mathrm{cp}\right.$ : 15-II-1918).

${ }^{48}$ T. Bretón: Elegía y añoranzas (39. ${ }^{\circ} \mathrm{cp}:$ 30-XI-1917).

${ }^{49}$ L. Aula: Añoranzas, fragmento sinfónico (56. ${ }^{\circ} \mathrm{cp}:$ 24-I-1919).

${ }^{50}$ B. Pérez Casas: ¡A mi tierra! (Escenas murcianas), tres tiempos (13. $\left.{ }^{\circ} \mathrm{cp}: 17-X I 1-1915\right)$.

${ }^{51}$ J. Gómez: Suite en La (31. ${ }^{\circ} \mathrm{cp}$ : 23-II-1917).

${ }^{52}$ Véase Labajo, Joaquina: "Música y tradición: anotaciones sobre la mecánica de los procesos de cambio en las sociedades urbanas", Boletín de la Real Academia de Bellas Artes de San Fernando, n. ${ }^{\circ} 83$ (2. ${ }^{\circ}$ semestre de 1996), pp. 257-269.

${ }^{53}$ B. Pérez Casas: iA mi tierra! (Escenas murcianas) (13. ${ }^{\circ} \mathrm{cp}: 17-\mathrm{XII-}$

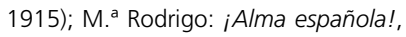
impresiones sinfónicas (34. $\mathrm{cp}$ : 16-III1917); P. J. A. de San Sebastián: Tres preludios vascos, para orquesta (37. cp: 16-XI-1917); E. López Chavarri: Valencianas, cuadros levantinos (40. ${ }^{\circ}$ cp: 7-XII-1917); A. Gaos: Granada, un atardecer en la Alhambra, poema sinfónico (61. $\left.{ }^{\circ} \mathrm{cp}: 28-\| 1-1919\right)$; B. García de la Parra: Tríptico gallego (103. cp: 2-XII-1921); F. Moreno Torroba: Cuadros castellanos (102. ${ }^{\circ}$ cp: 25 de noviembre de 1921).

${ }^{54}$ A. Bretón: Fantasía gitana (29. ${ }^{\circ}$ cp: 9-II-1917); J. Gómez: Suite en La (31. ${ }^{\circ}$ cp: 23-II-1917); P. J. A. de San Sebastián: Tres preludios vascos, para orquesta (37. $\left.{ }^{\circ} \mathrm{cp}: 16-\mathrm{XI}-1917\right) ; \mathrm{E}$. López Chavarri: Valencianas, cuadros levantinos (40. ${ }^{\circ} \mathrm{cp}:$ 7-XII-1917); M. de Falla: Noches en los jardines de España, impresiones sinfónicas para piano y orquesta (46. $\left.{ }^{\circ} \mathrm{cp}: 15-\| 1-1918\right) ;$ F. de la Viña: Por tierras de Castilla, evocación sinfónica (75. ${ }^{\circ} \mathrm{cp}$ : 20-II-1920); J. R. Blanco-Recio: Égloga, boceto sinfónico (77. ${ }^{\circ} \mathrm{cp}$ : 5-III-1920); M. de Falla: El sombrero de tres picos (tres danzas), versión de concierto extractada del "ballet" (106. cp: 13-I-1922); A. Barrios: Impresiones de GranadaZambra en el Albaicín (135. ${ }^{\circ} \mathrm{cp}$ : $14-$ XII-1923); J. Turina: Sinfonía sevillana (135. ${ }^{\circ} \mathrm{cp}:$ 14-XII-1923).

${ }^{55}$ M. López Roberts: La leyenda de Santa Casilda, poema sinfónico con instrumentación de T. Valdovinos (49. $\left.{ }^{\circ} \mathrm{cp}: 12-1 \mathrm{II}-1918\right) ; \mathrm{F}$. Moreno Torroba: Cuadros (70. ${ }^{\circ} \mathrm{cp}:$ 19-XII-1919); Vives: Preludio de Pepe Botellas (95. cp: 4-III-1921); T. Bretón: Panaderos, baile español y Bolero, baile popular (100. $\left.{ }^{\circ} \mathrm{cp}: 11-\mathrm{Xl}-1921\right)$.

${ }^{56} \mathrm{M}$. de Falla: Noches en los jardines de España, impresiones sinfónicas para piano y orquesta $\left(46 .^{\circ} \mathrm{cp}\right.$ : 15-II-1918).

${ }^{57}$ J. Guridi: Una aventura de don
Quijote, poema sinfónico (22. ${ }^{\circ} \mathrm{cp}: 17-$ XI-1916); J. Turina: La procesión del Rocío, cuadro sinfónico (30. ${ }^{\circ} \mathrm{cp}: 16-$-II1917); P. J. A. de San Sebastián: Cuatro preludios vascos, segunda serie (67. ${ }^{\circ}$ cp: 28-XI-1919); F. de la Viña: Por tierras de Castilla, evocación sinfónica (75. cp: 20-II-1920); J. R. BlancoRecio: Égloga, boceto sinfónico (77. ${ }^{\circ}$ cp: 5-III-1920); F. de la Viña: Covadonga (144. ${ }^{\circ}$ cp: 9-II-1924).

${ }^{58}$ Mainer, José Carlos: "La invención estética de las periferias". En: Centro y periferia en la modernización de la pintura española (1880-1918). Madrid: Centro Nacional de Exposiciones y Promoción Artística, 1993, p. 30.

${ }^{59}$ Adolfo Salazar escribió párrafos muy despectivos sobre el regionalismo, como este: "Cosa curiosa, ese movimiento que tiene una aspiración nacional como su nombre indica, ha producido en España, explotado por autores de distinta categoría, un fenómeno que en esencia es antitético al concepto nacional: el regionalismo. Para un número muy abundante de compositores [...], el problema era de una índole local, provincial, regional. La posibilidad de trascender al movimiento europeo, mundial, en calidad de nación musical, quedaba reducida en ellos a una actividad cerrada y conclusa en el término de la región, de la provincia". Salazar, Adolfo: La música contemporánea en España. Madrid: La Nave, 1930. Reedición facsimilar, Universidad de Oviedo, 1982, p. 268. Ese desprecio hacia el regionalismo ha comenzado a rebatirse en trabajos como el de Archilés Cardona, Ferrán: "Hacer región es hacer patria. La región en el imaginario de la nación española de la Restauración", Ayer, n. ${ }^{\circ} 64$ (2006), pp. 121-147.

60 "No puede darse localidad más adecuada para el caso. Merced a las medianas comunicaciones para el tráfico y viajes a Guipúzcoa y al resto de Navarra, y más en contacto hasta hace pocos años con el Labourd francés que con nosotros, en esa pintoresca y deliciosa comarca se han podido conservar, y se conservan de hecho, los 
cantares populares con una fuerza desconocida, por desgracia, en otras regiones". Cita de Gascue incluida en las notas de P. J. A. de San Sebastián: Tres preludios vascos, para orquesta (37. ${ }^{\circ} \mathrm{cp}: 16-\mathrm{XI}-1917$ ).

61 B. Pérez Casas: ¡A mi tierra! (Escenas murcianas), tres tiempos (13. ${ }^{\circ} \mathrm{cp}:$ 17-XII-1915); I. Albéniz: Catalonia, suite popular (23. $\mathrm{cp}$ : $24-$ XI-1916); T. Bretón: Salamanca, poema sinfónico (24. ${ }^{\circ} \mathrm{cp}$ : 1-XII-1916); P. J. A. de San Sebastián: Tres preludios vascos, para orquesta $\left(37 .{ }^{\circ} \mathrm{cp}: 16-\mathrm{XI}-\right.$ 1917)y Cuatro preludios vascos, segunda serie (67. ${ }^{\circ} \mathrm{cp}$ : 28-XI-1919); E. López Chavarri: Valencianas, cuadros levantinos (40. ${ }^{\circ} \mathrm{cp}$ : 7-XII-1917); B. García de la Parra: Tríptico gallego (103. ${ }^{\circ} \mathrm{cp}:$ 2-XII-1921); L. Vega: Rapsodias de la Mancha (105. ${ }^{\circ} \mathrm{cp}: 16-\mathrm{XII-}$ 1921).

62 J. Turina: La procesión del Rocío, cuadro sinfónico $\left(30{ }^{\circ} \mathrm{cp}\right.$ : $16-$-II1917).

63 "La 'suite' Añoranzas está dividida en cuatro tiempos, fundándose todos ellos en recuerdos de cantos y ritmos populares (formando temas originales, no transcritos), de los que es tan rica aquella región y que el músico, lejos de ella, recuerda con melancolía". P. Blanco: Añoranzas, suite española (45. ${ }^{\circ} \mathrm{cp}:$ 8-II-1918).

${ }^{64}$ Véase al respecto el esclarecedor trabajo de Torres Clemente, Elena: "La imagen de Manuel de Falla en la crítica de Adolfo Salazar". En: Música y cultura en la Edad de Plata, 19151939. M. Nagore, L. Sánchez de Andrés, E. Torres (eds.). Madrid: ICCMU, 2009, pp. 265-285.

${ }^{65} \mathrm{M}$. de Falla: Noches en los jardines de España, impresiones sinfónicas para piano y orquesta $\left(46 .^{\circ} \mathrm{cp}\right.$ : 15-II- 1918).

${ }^{66}$ Proceden de óperas, zarzuelas y ballets los siguientes fragmentos: Intermedio de Goyescas (E. Granados), Escena de amor de Jimena y Rodrigo (M. Manrique de Lara), Intermedio de La llama (R. de Usandizaga), Preludio de La Revoltosa (R. Chapí), Intermedio de La boda de Luis Alonso (G. Gimé- nez), Preludio de Garín (T. Bretón), Preludio de Pepe Botellas (A. Vives), Jota de La Dolores (T. Bretón), Suite sinfónica extractada de Amaya (J. Guridi) y Suite del ballet El sombrero de tres picos (M. de Falla).

${ }^{67}$ Los galeotes (T. Bretón), Una aventura de don Quijote (J. Guridi), Salamanca (T. Bretón), Sierra de Gredos (F. de la Viña), La leyenda de Santa Casilda (M. López Roberts), Granada, un atardecer en la Alhambra (A. Gaos), La primera salida de don Quijote (E. Serrano) y Kasida (C. del Campo).

${ }^{68}$ E. Serrano: Elegía a la memoria de Fernando Villamil $\left(11 .^{\circ} \mathrm{cp}: 10-\mathrm{XII}-\right.$ 1915).

69 F. Moreno Torroba: Cuadros castellanos (102. ${ }^{\circ} \mathrm{cp}:$ 25-XI-1921).

70 A. Vives: Preludio de Pepe Botellas (95. ${ }^{\circ} \mathrm{cp}:$ 4-III-1921).

${ }^{71}$ F. de la Viña: Covadonga, evocación sinfónica (144. ${ }^{\circ} \mathrm{cp}$ : 29-II-1924).

${ }^{72}$ Me refiero al concepto extensamente desarrollado en Les lieux de mémoire. P. Nora (ed.). Paris: Gallimard, 1997, 3 vols.

${ }^{73}$ Sobre esta temática particular, véase Martínez del Fresno, Beatriz: "La Edad Media revisitada. Historia y mito en la música española (1900-1950)" En: Scripta, Estudios en homenaje a Elida García García. Servicio de Publicaciones de la Universidad de Oviedo, 1998, vol. II, pp. 887-902. Más tarde, en el franquismo, las épocas de los Reyes Católicos y el siglo de Oro pasarán al primer plano y algunos musicólogos negarán los componentes árabes y judíos de la música española.

${ }^{74}$ Conrado del Campo: Kasida, poema sinfónico (110. ${ }^{\circ} \mathrm{cp}: 10-11-$ 1922). Esta obra fue premiada en el concurso organizado en 1920 por el Gran Casino de San Sebastián.

${ }^{75}$ El Universo, recorte sin fecha sobre el $8 .^{\circ} \mathrm{cp}$. Las fuentes hemerográficas que mencionaré sin fecha se conservan en el Archivo del Círculo de Bellas Artes.

76 El Parlamentario, recorte sin fecha sobre el $12{ }^{\circ} \mathrm{cp}$.
77 Así se señala en $A B C, 11-\mathrm{XI}-$ 1916. En alguna de las liquidaciones se menciona, por ejemplo, entre los gastos, "Continental Express, por traslado de decoración y tablado desde el Pabellón del Retiro al Teatro... 30,00 pesetas" (Boletín del Círculo de Bellas Artes, n. ${ }^{\circ}$ 47, enero de 1917, p. 8). Heraldo de Madrid describe del siguiente modo la decoración del concierto extraordinario celebrado para aumentar los fondos destinados a la erección del monumento al pintor Rosales: "En el escenario se había colocado un magnífico y grandioso busto de Rosales, obra improvisada en pocos días por el joven y notable escultor Jesús María Perdigón, muy bien modelada, de gran carácter y parecido. Al fondo, sobre la decoración, el tapiz de la Minerva del Círculo. Sobre la barandilla de la galería alta figuraban la colección de tapices pintados del citado centro artístico y un acertado adorno de plantas, improvisado por el jardinero del Ayuntamiento, completaban la decoración de la sala". J. B. C.: "Fiesta musical en Price", Heraldo de Madrid, citado en Boletín del Círculo de Bellas Artes, n. ${ }^{\circ}$ 58, diciembre de 1917, p. 8.

78 Borrell Vidal, José: Sesenta años de música (1876-1936)..., p. 174. Cuando los conciertos sinfónicos adquirieron estabilidad se aprobó una Comisión permanente que se encargaba de su organización. En ella trabajaron los señores Monen, Rafael Martínez Lage, José Borrell Vidal, Antonio Urgellés y Mariano Villahermosa, reforzando a los miembros de la Mesa de la Sección de Música. José Borrell fue además presidente de la Sección de Música en 1920 aunque solo por unos meses, ya que dimitió en julio del citado año.

${ }^{79}$ El Mundo, recorte sobre el 11. cp. En los programas de los conciertos populares se repite la prohibición de fumar en la sala.

${ }^{80}$ El Imparcial (M. M.), 2-XII1916.

${ }^{81}$ La Mañana (D. de V.), recorte sobre el $10{ }^{\circ} \mathrm{cp}$. 
${ }^{82}$ ABC, 23-XII-1916.

${ }^{83}$ Borrell Vidal, José: Sesenta años de música (1876-1936)..., p. 174.

${ }^{84}$ Recortes diversos sobre conciertos comprendidos entre el $8 .^{\circ}$ y el 20. (El Debate, ABC, La Época, El Imparcial, La Correspondencia de España). Archivo del Círculo de Bellas Artes.

${ }^{85}$ La Época, 8. ${ }^{\circ} \mathrm{cp}$. La Sociedad de Conciertos (1866-1903) fue la precursora de la Orquesta Sinfónica de Madrid.

${ }^{86}$ El Imparcial, $15 .^{\circ} \mathrm{cp}$.

${ }^{87} \mathrm{ABC}, 7-11-1915$.

${ }^{88}$ El Liberal, $20{ }^{\circ} \mathrm{cp}$.

${ }^{89}$ Sobre el concierto-tipo de la Orquesta Filarmónica de Madrid, véase Cuadrado Caparrós, María Dolores: Bartolomé Pérez Casas y la Orquesta Filarmónica de Madrid (1915-1936). Valencia: Germania, 2007, pp. 186-192.

${ }^{90}$ ABC: 23-I-1915.

${ }^{91}$ Así lo afirma José Subirá en la Revista Musical Hispano-Americana, 30-XI-1916.

92 Ibid., 21-XII-1916.

93 "Un momento vacilante, el auditorio reaccionó pronto en una imponente protesta contra injustificadas intransigencias, y tributó un calu- roso homenaje de aplausos al ilustre compositor". ABC, 16-XII-1917.

${ }^{94}$ Después de ese fracaso Abelardo Bretón dejó de componer. Véase Sánchez, Víctor: Tomás Bretón. Un músico de la Restauración. Madrid: ICCMU, 2002, p. 455.

${ }_{95}$ Villar, Rogelio: El sentimiento nacional en la música española. Madrid: s. n., s. a. [ca. 1920].

${ }^{96}$ R. V.: El País, sobre el $10 .{ }^{\circ} \mathrm{cp}$.

97 Reglamento de la Sociedad Nacional de Música, presentado en la Dirección General de Seguridad el 17XII-1917, p. 7.

${ }^{98}$ Subirá, José, en Revista Musical Hispano-Americana, 30-XI-1916, p. 9.

${ }^{99}$ En mi monografía sobre el compositor dedico un capítulo a estudiar en profundidad la obra, su recepción y las polémicas que se produjeron en la prensa madrileña después del estreno. Martínez del Fresno, Beatriz: Julio Gómez. Una época de la música española. Madrid: ICCMU, 1999, pp. 121-155.

100 Smith, Anthony D.: La identidad nacional. Madrid: Trama, 1997, p. 71.

101 Algunos aspectos sociales de la música de esta época son tratados en Martínez del Fresno, Beatriz: "Los lenguajes musicales de la Edad de
Plata: modernidad, elitismo y popularismo en torno a 1927". En: Música y cultura en la Edad de Plata, 19151939. M. Nagore, L. Sánchez de Andrés, E. Torres (eds.). Madrid: ICCMU, 2009, pp. 455-478. Varias entidades musicales del período se estudian en el monográfico dedicado al "Asociacionismo musical en España", Cuadernos de Música Iberoamericana, n. ${ }^{\circ}$ 8-9 (2001), entre ellas, la Sociedad Nacional de Música (por Emilio Casares) y las orquestas y sociedades musicales del primer tercio del siglo XX en Barcelona (por Francesc Bonastre y Xosé Aviñoa). Véase también el libro colectivo Música española entre dos guerras, 1914-1945. J. Suárez-Pajares (ed.). Granada: Archivo Manuel de Falla, 2002. Un seguimiento pormenorizado de la vida musical madrileña a partir de 1923 se encuentra en Palacios, María: La renovación musical en Madrid durante la dictadura de Primo de Rivera. El grupo de los Ocho (1923-1931). Madrid: Sociedad Española de Musicología, 2008.

102 Decreto por el que se crea la Junta Nacional de Música y Teatros Líricos, de fecha 21-VII-1931 (Gaceta del 22). Citado en La Música en la Generación del 27. Homenaje a Lorca, 1915-1939. E. Casares (coord.). Madrid: INAEM, 1986, p. 256 